\title{
BROOKHGWEN
}

NATIONAL LABORATORY

BNL-112627-2016-JA

\section{QUANTIFYING THE INFLUENCES OF SPECTRAL RESOLUTION ON UNCERTAINTY IN LEAF TRAIT ESTIMATES THROUGH A BAYESIAN APPROACH TO RTM INVERSION}

\author{
Alexey N. Shiklomanov, Michael C. Dietze, \\ Toni Viskari, Philip A. Townsend, Shawn P. Serbin
}

Accepted for publication in Sensing of Environment

September 2016

\author{
Environmental \& Climate Science Department \\ Brookhaven National Laboratory
}

\section{U.S. Department of Energy USDOE Office of Science (SC), Biological and Environmental Research (BER) (SC-23)}

Notice: This manuscript has been authored by employees of Brookhaven Science Associates, LLC under Contract No. DESC0012704 with the U.S. Department of Energy. The publisher by accepting the manuscript for publication acknowledges that the United States Government retains a non-exclusive, paid-up, irrevocable, world-wide license to publish or reproduce the published form of this manuscript, or allow others to do so, for United States Government purposes. 


\section{DISCLAIMER}

This report was prepared as an account of work sponsored by an agency of the United States Government. Neither the United States Government nor any agency thereof, nor any of their employees, nor any of their contractors, subcontractors, or their employees, makes any warranty, express or implied, or assumes any legal liability or responsibility for the accuracy, completeness, or any third party's use or the results of such use of any information, apparatus, product, or process disclosed, or represents that its use would not infringe privately owned rights. Reference herein to any specific commercial product, process, or service by trade name, trademark, manufacturer, or otherwise, does not necessarily constitute or imply its endorsement, recommendation, or favoring by the United States Government or any agency thereof or its contractors or subcontractors. The views and opinions of authors expressed herein do not necessarily state or reflect those of the United States Government or any agency thereof. 


\title{
1 Quantifying the influences of spectral resolution on 2 uncertainty in leaf trait estimates through a Bayesian 3 approach to RTM inversion
}

4

6

7

8

9
10

10

11

12

13

14

\author{
Authors: Alexey N. Shiklomanov ${ }^{1}$, Michael C. Dietze ${ }^{1}$, Toni Viskari ${ }^{23}$, Philip A. Townsend ${ }^{4}$, \\ Shawn P. Serbin ${ }^{23}$ \\ Keywords: Leaf optical properties, PROSPECT, radiative transfer modeling, hyperspectral data, \\ Bayesian statistics, spectral inversion \\ Corresponding author: \\ Alexey Shiklomanov \\ ashiklom@bu.edu
}

${ }^{1}$ Department of Earth \& Environment, Boston University, Boston, MA, USA

${ }^{2}$ Environmental \& Climate Sciences Department, Brookhaven National Laboratory, Upton, NY, USA

${ }^{3}$ Sustainability Studies, Stony Brook University, Stony Brook, NY, USA

${ }^{4}$ Department of Forest and Wildlife Ecology, University of Wisconsin-Madison, Madison, WI, USA 
Abstract

16 The remote monitoring of plant canopies is critically needed for understanding of terrestrial

17 ecosystem mechanics and biodiversity as well as capturing the short- to long-term responses of

18 vegetation to disturbance and climate change. A variety of orbital, sub-orbital, and field

19 instruments have been used to retrieve optical spectral signals and to study different vegetation

20 properties such as plant biochemistry, nutrient cycling, physiology, water status, and stress.

21 Radiative transfer models (RTMs) provide a mechanistic link between vegetation properties and

22 observed spectral features, and RTM spectral inversion is a useful framework for estimating

23 these properties from spectral data. However, existing approaches to RTM spectral inversion are

24 typically limited by the inability to characterize uncertainty in parameter estimates. Here, we

25 introduce a Bayesian algorithm for the spectral inversion of the PROSPECT 5 leaf RTM that is

26 distinct from past approaches in two important ways: First, the algorithm only uses reflectance

27 and does not require transmittance observations, which have been plagued by a variety of

28 measurement and equipment challenges. Second, the output is not a point estimate for each

29 parameter but rather the joint probability distribution that includes estimates of parameter

30 uncertainties and covariance structure. We validated our inversion approach using a database of

31 leaf spectra together with measurements of equivalent water thickness (EWT) and leaf dry mass

32 per unit area (LMA). The parameters estimated by our inversion were able to accurately

33 reproduce the observed reflectance $\left(\mathrm{RMSE}_{\mathrm{VIS}}=0.0063, \mathrm{RMSE}_{\mathrm{NIR}-\mathrm{SWIR}}=0.0098\right)$ and

34 transmittance $\left(\mathrm{RMSE}_{\mathrm{VIS}}=0.0404, \mathrm{RMSE}_{\mathrm{NIR}-\mathrm{SWIR}}=0.0551\right)$ for both broadleaved and conifer

35 species. Inversion estimates of EWT and LMA for broadleaved species agreed well with direct

36 measurements $\left(\mathrm{CV}_{\mathrm{EWT}}=18.8 \%, \mathrm{CV}_{\mathrm{LMA}}=24.5 \%\right)$, while estimates for conifer species were less

37 accurate $\left(\mathrm{CV}_{\mathrm{EWT}}=53.2 \%, \mathrm{CV}_{\mathrm{LMA}}=63.3 \%\right)$. To examine the influence of spectral resolution on 
38 parameter uncertainty, we simulated leaf reflectance as observed by ten common remote sensing

39 platforms with varying spectral configurations and performed a Bayesian inversion on the

40 resulting spectra. We found that full-range hyperspectral platforms were able to retrieve all

41 parameters accurately and precisely, while the parameter estimates of multispectral platforms

42 were much less precise and prone to bias at high and low values. We also observed that

43 variations in the width and location of spectral bands influenced the shape of the covariance

44 structure of parameter estimates. Our Bayesian spectral inversion provides a powerful and

45 versatile framework for future RTM development and single- and multi-instrumental remote

46 sensing of vegetation. 


\section{1. Introduction}

The terrestrial biosphere is fundamentally dependent on the interactions between plants

49 and solar radiation through photosynthesis. Consequently, we can learn a lot about the structure

50 and functioning of ecosystems by studying these interactions in detail, and over the last several

51 decades our capability do so has expanded dramatically. Specifically, global scale remote

52 sensing observations from satellites such as Landsat, MODIS, and AVHRR have been used to

53 map and monitor vegetation productivity, distribution, and abundance at high temporal

54 frequency (Loveland et al. 2000; Friedl et al. 2002; Hansen et al. 2010; Houborg et al. 2015). At

55 the landscape scale, satellite and sub-orbital (airborne) platforms with high spatial (e.g.

56 WorldView, $<1 \mathrm{~m}$ ) and/or spectral (e.g. AVIRIS Classic, $10 \mathrm{~nm}$ ) resolution sensors have been

57 able to quantify the spatial distribution of canopy structure, nutrient status, and species

58 composition (Asner et al. 2015; Banskota et al. 2015; Singh et al. 2015). In addition, field

59 spectrometers with the highest available spectral resolution have provided a fast and relatively

60 simple method for characterizing and monitoring leaf physiology, biochemistry, and morphology

61 (Serbin et al. 2012; Couture et al. 2013; Sullivan et al. 2013; Serbin et al. 2014; Zhao et al. 62 2014).

63 An important caveat of using spectral information to study vegetation is that the optical

64 properties being measured are often not of primary interest. Rather, we are interested in

65 physiologically or ecologically meaningful variables such as total biomass, photosynthetic

66 efficiency, species composition, biomass, or biochemistry that drive observed spectral signatures

67 of vegetation (Curran, 1989) and which can be inferred from the optical properties. This

68 connection is usually made empirically, either by simple regression with spectral vegetation

69 indices (SVIs) (Fassnacht et al. 2015; Haboudane et al. 2002; Huete et al. 2002) or through more 
70 advanced statistical methods such as partial least squares regression (PLSR) (Couture et al. 2013;

71 Serbin et al. 2012, 2014; Singh et al. 2015) and wavelet transforms (Banskota et al. 2013;

72 Blackburn \& Ferwerda 2008; Cheng et al. 2010). However, these approaches can have important

73 limitations depending on the application. First, the empirical nature of these methods can result

74 in sensor, site, and/or vegetation specific relationships, as evidenced by the substantial variability

75 in coefficients and choice of wavelengths across studies (Croft et al. 2014; Huete et al. 2002;

76 Knyazikhin et al. 1998; Leprieur et al. 1994; Liu et al. 2012; Myneni et al. 2002; Wessels et al.

77 2012). Second, empirical approaches are not a direct mechanistic relationship between spectra

78 and plant properties and therefore do not provide the true connections between optical properties

79 and variables of interest (Knyazikhin et al. 2013). As a result, extrapolating empirical approaches

80 and relationships to larger regions or new locations can be challenging. Moreover, the indirect,

81 derived data products that arise from such analyses may have a limited capacity to inform

82 ecosystem models (Quaife et al., 2008), as they often introduce assumptions that conflict with

83 the internal logic of the processes represented in these models.

84 In contrast, radiative transfer models (RTMs), which provide a more mechanistic link

85 between plant traits and spectral signatures, can be a useful alternative to empirical approaches.

86 A variety of standalone RTMs exist from the leaf (Dawson et al. 1998; Feret et al. 2008; Ganapol

87 et al. 1998) to canopy scales (Jacquemoud et al. 2009; Kuusk 2001; Verhoef 1984; Wang \& Li

88 2013). In addition, RTMs are often an important component of dynamic vegetation models,

89 where they are used to calculate surface energy balance and light availability for photosynthesis

90 (Medvigy et al. 2009; Ni-Meister et al. 2010; Kobayashi et al. 2012). In this study, we focus on

91 the leaf-level PROSPECT model (Jaquemoud and Baret 1990), which has been extensively used

92 in forward (simulation) mode to develop and test new remote sensing techniques (Croft et al. 
93 2014; Féret et al. 2011; Hunt et al. 2012; le Maire et al. 2004; Zarco-Tejada et al. 2013) as well

94 as to estimate leaf traits from spectral observations via inversion (Atzberger \& Richter 2012;

95 Feret et al. 2008; Jacquemoud et al. 1995; Jacquemoud et al. 2009; Li \& Wang 2013; Li \& Wang

96 2011; Zarco-Tejada et al. 2004). However, the commonly used approaches for RTM inversion-

97 such as least-squares minimization and look-up tables — fail to directly quantify the uncertainties

98 and account for the correlations among the resulting parameter estimates. The characterization of

99 uncertainty is a fundamental requirement for drawing meaningful scientific conclusions from

100 results and for assimilating results into statistical or mechanistic models (Cressie et al. 2009;

101 Quaife et al. 2008).

102 Applying Bayesian statistics to RTM inversion activities provides a direct means to

103 quantify the uncertainty and covariance of parameter estimates while combining multiple sources

104 of information. The use of independent prior information has been a critical component of RTM

105 inversion as a way to solve the otherwise underdetermined problem of estimating a large number

106 of RTM parameters from a small number of observations (Combal et al. 2003, Lauvernet et al.

107 2008, Yao et al. 2008; Pinty et al. 2011; Zhang et al. 2012; Laurent et al. 2014; Mousivand et al.

108 2015). While these studies either neglect parameter uncertainty or estimate it using

109 computationally-efficient approximations (e.g. Gaussian posterior distributions), recent work has

110 demonstrated the efficacy of fully-Bayesian Markov Chain Monte Carlo (MCMC) approaches

111 for inversion of the PROSAIL canopy RTM using MODIS (and "MODIS-like") data (Zhang et

112 al. 2005, 2006, 2009, \& 2011). However, to the authors' knowledge, such approaches have yet to

113 be applied to hyperspectral data, neither at the canopy nor the leaf scales. A recent study by

114 Lepine et al. (2016) further demonstrated that PLSR estimates of canopy nitrogen are less

115 sensitive to spectral resolution than spatial resolution and sensor fidelity, but no comparable 
116 analyses has been attempted for other foliar constituents, nor, for that matter, using a physically-

117 based RTM rather than an empirical regression. In this study, we examine the effects of

118 measurement spectral characteristics on accuracy, uncertainty, and covariance of leaf traits

119 estimated from spectral inversion of a leaf RTM. First, we demonstrate the applicability of a

120 fully Bayesian approach to leaf RTM inversion and validate this approach using data from the

121 NASA Forest Functional Types (FFT) database of field spectra (Serbin et al., 2014; Singh et al.,

122 2015). Second, we simulate reflectance observations using the spectral response functions of ten

123 common remote sensing platforms and test the accuracy and precision with which our inversion

124 algorithm can retrieve parameters from these observations. Although such an experiment is

125 highly idealized, it does provide insight on the absolute theoretical limits of RTM inversion by

126 different remote sensing platforms and illustrates how subtle changes in spectral measurement

127 characteristics can affect inversion results. More broadly, this work reiterates the power of a

128 Bayesian framework for fully utilizing the vast archive of remote sensing and field spectral

129 observations to enhance our understanding of ecosystem processes.

130 2. Methods

131 2.1. Inversion procedure

132 The PROSPECT 5 model simulates the full spectral reflectance and transmittance of a

133 leaf over the $400-2500 \mathrm{~nm}$ range using five key parameters related to leaf structure and

134 biochemistry (Feret et al. 2008). In the PROSPECT model, a leaf is treated as a set of $N$ partially

135 transparent flat plates, each with wavelength-dependent transmissivity $k_{\lambda}$. Transmissivity $k_{\lambda}$ is

136 based on the linear combination of empirically calibrated specific absorption spectra for total

137 chlorophyll ( $a$ and $b$ ), total carotenoids, water, and dry matter (e.g. cellulose, lignin, protein) 
multiplied by their respective quantities (given by the parameter values: $\mathrm{Cab}, \mathrm{Car}, \mathrm{Cw}, \mathrm{Cm}$ )

139 (Table 1; Figure S1). For further detail on the PROSPECT model, see Feret et al. (2008).

140 Table 1 Summary of PROSPECT 5 parameters. Ranges for Car, Cw, and Cm are based on the 141 datasets used for their calibration (ANGERS for Cab and Car, LOPEX for $\mathrm{Cw}$ and $\mathrm{Cm}$ ) as 142 reported in Feret et al. (2008). The ranges for $\mathrm{N}$ and $\mathrm{Cab}$ are calculated from the LOPEX and 143 ANGERS databases, respectively (available online at http://opticleaf.ipgp.fr or on request). Units 144 for $\mathrm{Cw}$ and $\mathrm{Cm}$ are adjusted for readability (original units are $\mathrm{g} \mathrm{cm}^{-2}$ ).

\begin{tabular}{llll} 
Parameter & Description & Unit & Range \\
\hline $\mathrm{N}$ & $\begin{array}{l}\text { Structural parameter; effective number of } \\
\text { mesophyll layers }\end{array}$ & Unitless & 1.09 to 3.00 \\
$\mathrm{Cab}$ & Total chlorophyll $(a$ and $b$ ) density & $\mu \mathrm{g} \mathrm{cm}^{-2}$ & 0.78 to 106.72 \\
$\mathrm{Car}$ & Total carotenoid density & $\mu \mathrm{g} \mathrm{cm}^{-2}$ & 0 to 25.3 \\
$\mathrm{Cw}$ & Equivalent water thickness & $\mathrm{g} \mathrm{m}^{-2}$ & 43 to 439 \\
$\mathrm{Cm}$ & Leaf dry matter content per unit area & $\mathrm{g} \mathrm{m}^{-2}$ & 17 to 152
\end{tabular}

147 from the observed spectral information. This is accomplished through a statistical inversion, 148 wherein we seek the set of parameters that minimizes the residual error between PROSPECT149 modeled and measured reflectance. Our approach to the inversion of PROSPECT is distinct from 150 previous studies (Combal et al. 2003; Feret et al. 2008; Féret et al. 2011; Li \& Wang 2011, 2013)

151 in two important ways. First, whereas many past studies use both reflectance and transmittance

152 to estimate parameters, we use only reflectance. Reflectance is generally easier to measure than

153 transmittance, which requires special instrumentation such as integrating spheres that often have

154 inadequate designs and yield poor signal-to-noise ratios, especially in the longer wavelengths

155 (i.e. $>2 \mu \mathrm{m}$ ). As well, inversion on reflectance data alone allows transmittance measurements as

156 optional data for independent validation. Second, unlike past leaf-level PROSPECT inversion

157 studies that only provide point estimates of parameters, we performed our analysis within a 
158 Bayesian framework that provides the joint probability distribution of the PROSPECT 5

159 parameters, $\theta=\{\mathrm{N}, \mathrm{Cab}, \mathrm{Car}, \mathrm{Cw}, \mathrm{Cm}\}$, and the residual standard deviation, $\sigma$, as the output.

160 The general mathematical statement of this posterior distribution is given as follows:

$$
P(\theta, \sigma \mid X) \propto P(X \mid \theta, \sigma) P(\theta) P(\sigma)
$$

$$
P(X \mid \theta, \sigma) \propto \operatorname{Normal}(\operatorname{PROSPECT} 5(\theta) \mid X, \sigma),
$$

162 where $\operatorname{PROSPECT} 5(\theta)$ is the modeled reflectance given $\theta$, and $X$ is a vector of observed

163 reflectance values. The residual error is assumed to be normally distributed with a mean of 0 and 164 standard deviation of $\sigma$.

165 We set the prior distribution for $\mathrm{N}$ to a lognormal distribution shifted to have a minimum 166 of 1, and parameterized based on a review of literature using the PROSPECT model (le Maire et 167 al. 2004; Ferreira et al. 2013; Croft et al. 2014) (Figure S2). We assigned the remaining 168 parameters log-normal priors based on summary statistics and histograms from the LOPEX, 169 ANGERS, HAWAII, and CALMIT spectral databases as reported by Feret et al. (2008) (Figure 170 S2). The residual variance $\sigma^{2}$ was assigned an uninformative inverse gamma prior, which is 171 conjugate with the normal distribution and therefore allows for computationally efficient Gibbs 172 sampling.

173 We sampled the joint posterior distribution of the PROSPECT 5 parameters using the 174 Metropolis-Hastings (MH) algorithm with adaptive block sampling (Haario et al. 2001). For this, 175 we initialized each inversion using parameter values drawn at random from the prior 176 distributions. For each inversion, we ran the algorithm five times (i.e. five independent chains) 177 for 100,000 iterations each. At each iteration, the algorithm proposes a parameter vector, 178 calculates the vector's likelihood based on the observations and the prior, and accepts or rejects 179 the vector based on this likelihood. The proposal step performs a random draw from a 
180 multivariate normal distribution centered on the last accepted parameter vector. The covariance

181 matrix for the multivariate normal proposal distribution was re-computed every 100 iterations as

182 follows: (1) the univariate standard deviation of each parameter and the Pearson product-moment

183 correlation matrix were computed; (2) the standard deviation vector was multiplied by the ratio

184 of the acceptance rate in the last 100 samples to the target acceptance rate (set to 0.234 , as per

185 Haario et al. 2001); (3) the resulting standard deviation vector was converted to a diagonal

186 matrix and multiplied to both sides of the correlation matrix to give a re-scaled covariance

187 matrix. For each inversion, we determined MCMC convergence based on a value of the Gelman-

188 Rubin multivariate potential scale reduction factor of less than 1.1 (Gelman \& Rubin 1992, as

189 implemented in the R coda package v.0.18-1 by Plummer et al.). For runs that did not converge,

190 we repeated this process with a $20 \%$ smaller target acceptance rate for the adaptation step, which

191 increases the size of the sampling space for each chain and therefore reduces the likelihood of

192 getting trapped in local minima. Across the $>10,000$ inversions performed in this study, only five

193 failed to converge (after five inversion attempts) - all for simulated CHRIS-Proba spectra (see

194 Section 2.3) - and we excluded these data points from our analysis. We visually examined a

195 random subset of the resulting trace plots and autocorrelograms and determined that a common

196 burn-in period of 80,000 samples and a thinning interval of 20 was sufficient for an accurate and

197 representative sample of the joint posterior distribution. After applying the burn-in and thinning

198 filter, we calculated the mean, standard deviation, and 95\% confidence intervals of the sampled

199 parameter values (Figure S3).

200 With chains running in parallel, the inversion of one leaf spectrum with our specifications

201 takes approximately 4 minutes (on one Intel® Xeon ${ }^{\mathrm{TM}}$ X5570 CPU @ 2.93GHz), and running

202 the entire set of over 10,000 inversions required for this paper took several days (running up to 
20316 inversions simultaneously on a high performance computing cluster). That being said, we

204 anticipate that recoding of the algorithm from $\mathrm{R}$ to a compiled language will dramatically

205 increase (>50x) the computational efficiency of our approach.

206 The inversion algorithm described above is available as an open-source, publicly-

207 available R (R Development Core Team 2008) package housed within the PEcAn ecoinformatics

208 toolbox (github.com/pecanproject/pecan/tree/master/modules/rtm) (Dietze et al. 2013; LeBauer

209 et al. 2013). This package allows users to simulate spectra using the PROSPECT family of

210 radiative transfer models and apply our inversion algorithm to their own models and data. For

211 more information, refer to the package vignette on the PEcAn tutorials page

212 (pecanproject.github.io/tutorials.html).

\section{2.2. Validation}

214 2.2.1. Data

215 We tested the ability of our inversion to accurately estimate leaf traits using data

216 collected as part of the NASA Forest Functional Types (FFT) campaign (Deel et al. 2012; Serbin

217 et al. 2014; Singh et al. 2015). This dataset consists of leaves collected from various positions

218 within the canopy for 52 species from 13 sites across the Northeast and Midwest USA. An

219 Analytical Spectral Devices (ASD) FieldSpec 3 Full Range (350 to $2500 \mathrm{~nm}$ ) Spectroradiometer

220 was used together with a leaf clip and internal calibrated light source to measure reflectance on

221 the adaxial surface of 1348 unique leaves. For a subset of 765 of these leaves, the same

222 instrument was used with an ASD integrating sphere setup to measure transmittance through the

223 leaf adaxial surface. Our database included both broadleaf and conifer species. For conifer

224 measurements, we constructed edge-to-edge mats of needles larger than the spot size of the light

225 source (Serbin 2012, Singh et al. 2015). As detailed in Serbin (2012), we found minimal changes 
226 in reflectance/transmittance measurement up to a threshold of differing gaps between needles.

227 These observations are henceforth referred to as "FFT measured reflectance and transmittance,"

228 respectively. In addition to spectral measurements, laboratory measurements of leaf dry mass per

229 unit area (LMA) and equivalent water thickness (EWT) were available for 950 leaves. For

230 further information on the sampling methodology, see Serbin et al. (2014).

231 During exploratory analysis, we observed that inversion results by leaf habit displayed

232 some distinct differences and conifer species were consistently less accurate than results for

233 broadleaved species, reflecting ecological differences in leaf structure that are not well

234 represented by the PROSPECT model. Therefore, to better contextualize our results, we

235 performed both validation steps for the entire data set and separately for broadleaved and conifer

236 species. However, even within the conifer functional type, we found certain species and foliar

237 morphologies showed much larger errors than others. These differences could be ecological in

238 nature or an artifact related to the challenges of measuring full-range reflectance and

239 transmittance of different types of conifer needles. To investigate whether these errors aligned

240 with established ecological classifications, we grouped species based on their approximate

241 succession ("early", "mid", or "late"), following the general classification scheme of Dietze \&

242 Moorcroft (2011), except that we grouped the "Northern" and "Southern Pine" functional types

243 as "early conifer." Classification based on succession is useful for this study because it is

244 indicative of plant shade tolerance (Dietze \& Moorcroft 2011), which is closely linked to leaf

245 structure and biochemistry (Poorter et al. 2009).

246 We applied our inversion algorithm individually to each of the FFT measured reflectance

247 spectra $(n=1348)$, resulting in an estimate of the joint probability distribution of the

248 PROSPECT 5 parameters for each leaf. We then generated a dataset of synthetic reflectance 
spectra ("FFT simulated reflectance") by using the middle $90 \%$ of these parameter estimates ( $n=$

250 1040) as inputs to the PROSPECT 5 model. These synthetic reflectance spectra were used as

251 data in the sensor simulation experiment (Section 2.3). We used real parameter estimates rather

252 than random draws from a distribution to preserve their ecological ranges and covariances

253 resulting from within- and between-species tradeoffs in traits such as those described for the leaf

254 economics spectrum (Wright et al. 2004).

255 We then performed two different tests to evaluate the accuracy of these parameter

256 estimates: (1) We compared the FFT simulated reflectance and transmittance to measured

257 reflectance and transmittance, and (2) we directly compared the inversion estimates of

258 PROSPECT 5 parameters $C_{\mathrm{w}}$ and $C_{\mathrm{m}}$ to measured values of EWT and LMA, respectively.

\section{2.2.2. Reflectance and transmittance}

260 A common way to validate model inversion is to run the model in forward mode using

261 the estimated parameters as inputs and compare the output to the original data. For our study, we

262 used the inversion estimates of the PROSPECT parameters as inputs to the PROSPECT model to

263 predict reflectance and transmittance spectra, which we then compared to the observed

264 reflectance and transmittance. Errors in spectral inversion can originate from multiple sources,

265 including measurement error (both trait and spectra), failure of the PROSPECT model to fully

266 capture leaf spectral features (i.e. model formulation error), and parameter identifiability issues

267 in the inversion algorithm. To isolate algorithmic error, we first performed the validation on a set

268 of synthetic reflectance and transmittance spectra $(n=1348)$. To investigate the remaining

269 sources of error, we performed the same validation on FFT measured reflectance $(n=1348)$ and

270 transmittance $(n=765)$ spectra. For both reflectance and transmittance, we calculated the mean

271 and $90 \%$ and $95 \%$ confidence intervals on the absolute error (simulated - measured) at each 
272 wavelength. The overlap of the $95 \%$ confidence interval with 0 was used to judge statistical

273 significance. To facilitate comparison with other RTM inversion studies (Feret et al. 2008; Di

274 Vittorio 2009a), we also computed the root mean square error (RMSE), bias (BIAS), and bias-

275 corrected RMSE (SEPC) averaged across the visible (VIS, 400-800 nm) and near-infrared (NIR,

$276 \quad 801-2500 \mathrm{~nm}$ ) regions of the spectrum:

$$
\begin{gathered}
R M S E=\sqrt{\frac{\sum_{i}^{n}\left(x_{i}-x_{o}\right)^{2}}{n}} \\
B I A S=\frac{\sum_{i}^{n}\left(x_{i}-x_{o}\right)}{n} \\
S E P C=\sqrt{\frac{\sum_{i}^{n}\left(x_{i}-x_{o}-B I A S\right)^{2}}{n}},
\end{gathered}
$$

278 where $x_{i}$ is the simulated value (reflectance or transmittance), $x_{o}$ is the observed value, and $n$ is

279 the number of spectra considered.

\subsubsection{EWT and LMA}

For leaves that had paired measurements of reflectance and EWT and LMA $(n=950)$, we

282 compared the mean inversion estimates for PROSPECT parameters $\mathrm{Cw}$ and $\mathrm{Cm}$ to measured

283 values of EWT and LMA, respectively. For each, we compared the mean inversion estimate to

284 the measured value via the RMSE, BIAS, and SEPC as above (with inversion estimate $x$ and

285 measurement $x_{o}$ ) as well as relative RMSE (RMS\%E) and the relative bias-corrected RMSE

$286(\mathrm{CV})$ :

$$
\begin{aligned}
R M S \% E & =\sqrt{\frac{\sum_{i}^{n}\left(\frac{x_{i}-x_{o}}{x_{o}}\right)^{2}}{n}} \times 100 \% \\
C V & =\frac{S E P C}{x_{o b s}} \times 100 \%
\end{aligned}
$$


Table 2: Spectral, spatial, and temporal characteristics of several important previous and current remote sensing platforms and instruments considered in the sensor simulation experiment.

\begin{tabular}{cccccc} 
Sensor & $\begin{array}{c}\text { Number } \\
\text { of Bands }\end{array}$ & $\begin{array}{c}\text { Spectral range } \\
\text { (nm) }\end{array}$ & $\begin{array}{c}\text { Bandwidth } \\
\text { (nm) }\end{array}$ & $\begin{array}{c}\text { Spatial } \\
\text { resolution (m) }\end{array}$ & $\begin{array}{c}\text { Revisit time } \\
\text { (days) }\end{array}$ \\
\hline AVIRIS NG & 416 & 380 to 2510 & 5 & 0.3 to $4.0^{*}$ & On-demand \\
AVIRIS Classic & 216 & 400 to 2500 & 10 & $<10$ to $20^{*}$ & On-demand \\
CHRIS-Proba & 62 & 410 to 1050 & 1.5 to 12 & 36 & 7 to 8 \\
Hyperion & 225 & 350 to 2500 & 10 & 30 & 16 \\
Landsat 5 (TM) & 6 & 450 to 2350 & 60 to 270 & 30 & 16 \\
Landsat 7 (ETM+) & 6 & 440 to 2350 & 60 to 280 & 30 & 16 \\
Landsat 8 (OLI) & 8 & 435 to 2295 & 20 to 185 & 30 & 1 to 2 \\
MODIS & 7 & 459 to 2155 & 20 to 50 & 250 to 500 & 1 to 2 \\
VIIRS & 10 & 402 to 2275 & 15 to 60 & 750 & 1 \\
AVHRR & 3 & 580 to 1640 & 100 to 275 & 1090 & 16 \\
\hline
\end{tabular}

*Spatial resolution is dependent on aircraft altitude and instrument IFOV

\subsection{Sensor simulation experiment}

Recent work has shown that PLSR estimates of foliar nitrogen content are less sensitive

293 to spectral resolution than to other factors such as spatial resolution and sensor fidelity (Lepine et

294 al. 2016). However, the PLSR approach implemented in that study was unable to quantify the

295 uncertainty around the nitrogen estimates. We hypothesize that the spectral characteristics of

296 most common remote sensing platforms are sufficient to accurately estimate the leaf biophysical

297 parameters modeled by PROSPECT, but that the uncertainties in these parameters will increase

298 with declining spectral resolution. To test this hypothesis, we transformed the FFT simulated

299 reflectance spectra using the relative spectral response functions of 11 common remote sensing

300 platforms (Table 2, Figure S4), and used our Bayesian inversion of PROSPECT 5 to retrieve the 
301 starting parameters from the transformed spectra. For input parameters, we used the inversion

302 results from measured spectra, thereby capturing a large range of ecologically realistic values

303 and preserving inherent covariances between parameters. To account for observation error, we

304 simulated Gaussian random noise (with mean 0 and standard deviation $2.5 \times 10^{-4}$ ) smoothed with

305 a Gaussian filter (kernel width 11) to account for inherent autocorrelation in hyperspectral

306 measurements (Figure S5).

307 We then examined how two characteristics of the inversions varied between sensors:

308 Relative bias $(a)$ indicates how closely the mean parameter estimate $(\mu)$ matched the true value

$309(p)$ and is a useful measure for describing the accuracy of the estimate's central tendency.

$$
\alpha=\frac{\mu-p}{p}
$$

310 Uncertainty $(\pi)$ describes the width of the $95 \%$ confidence interval of the estimate $(s)$

311 relative to the mean value, and is useful for ascertaining the precision with which the inversion is

312 able to estimate a parameter.

$$
\pi=\frac{s}{\mu}
$$

313 We note that both statistics are normalized to facilitate inter-parameter comparison. Both

314 metrics were computed for each parameter for each inversion and then averaged over all

315 simulated spectra.

316 We recognize that this experiment does not fully capture all of the variability associated

317 with inversion of real observations from these sensor systems given its failure to account for

318 canopy structure, atmospheric effects, sun-sensor geometry, and sensor radiometric resolution.

319 However, this experiment is capable of illustrating the ability to characterize uncertainty in

320 inversion results and improves the confidence with which we can extract information from lower

321 quality data sources. Moreover, this experiment sets a theoretical limit on the accuracy and 
322 precision of leaf trait retrieval from spectral RTM inversion, thereby contextualizing past RTM

323 inversion results (e.g. Zhang et al. 2005, 2006, 2009, \& 2012) and guiding future research in the

324 field.

325 The entire workflow for this paper is summarized in Figure 1. The data and R source

326 code for performing all analyses in this study have been made publicly available at

327 github.com/ashiklom/sensor-manuscript. We encourage those interested to replicate our analyses 328 and build on them with their own data and models.

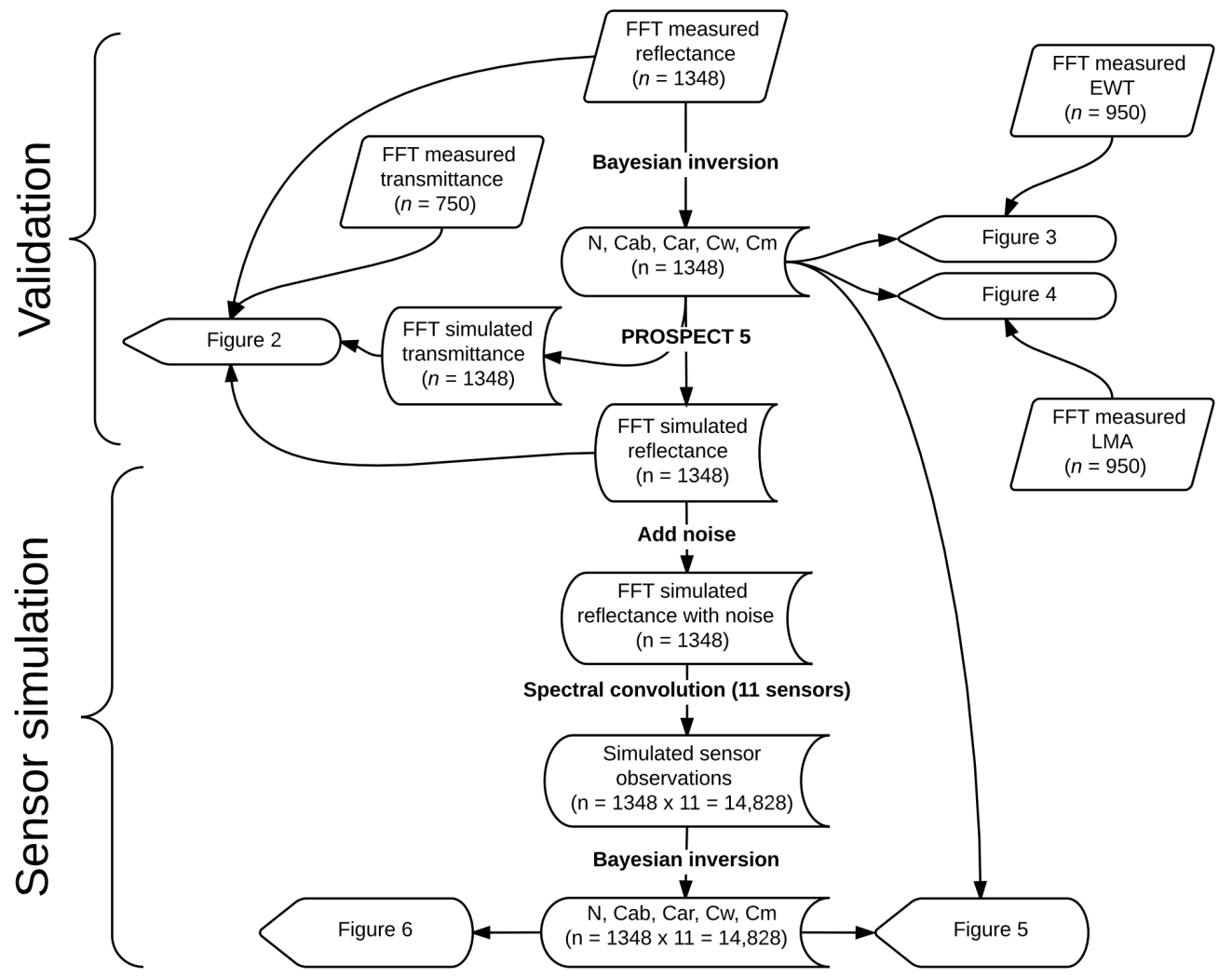

330 Figure 1 Workflow illustrating the steps in this study as well as the figures to which they 331 correspond. 


\section{3. Results}

\section{3.1. Validation}

\section{3.1.1. Reflectance and Transmittance}

335 For the inversion of synthetic spectra, we found no statistically significant $(p<0.05)$

336 spectral bias at any wavelength (Figure S6). As well, the observed differences between input and

337 simulated output were one to two orders of magnitude smaller than corresponding errors in the

338 inversion of measured spectra (Figure 2, Figure S6). These results collectively illustrate that our

339 algorithm is unbiased and contributes minimally to errors in the inversion of measured spectra.

340 For the inversion of measured spectra, we observed substantial variability in the spectral

341 bias across all analyzed leaves, resulting in statistically significant $(p<0.05)$ bias in only a few

342 specific wavelength regions (Figure 2). For both broadleaf and needle-leaf conifer species,

343 reflectance was typically overestimated between 1600 and $1900 \mathrm{~nm}$ and underestimated between

3441000 and $1300 \mathrm{~nm}$ and between 2000 and $2500 \mathrm{~nm}$. The errors in the 1600 to $1900 \mathrm{~nm}$ and 2000

345 to $2500 \mathrm{~nm}$ ranges covered more wavelengths and had larger magnitude for conifer species than

346 broadleaved species. Broadleaved species also had a statistically significant reflectance

347 overestimate in the 400 to $500 \mathrm{~nm}$ range and an underestimate at $1300 \mathrm{~nm}$, while conifer species

348 had a significant reflectance overestimate at $1300 \mathrm{~nm}$.

349 For both measured and synthetic spectra, transmittance bias (BIAS $=-0.0133$ ) was, on

350 average, greater in magnitude than reflectance bias (BIAS $=0.0018$ ), with a mean positive bias

351 for broadleaved species (BIAS $=0.0012)$ and a mean negative bias for conifer species (BIAS $=$

$352-0.0346$ ) (Figure 2, Table 3). However, the between-leaf variability in bias was also large and

353 resulted in statistically significant bias in only a small number of specific spectral regions. For

354 both broadleaved and conifer species, we observed a significant underestimate in transmittance 
in the chlorophyll $a$ absorption 400 and $500 \mathrm{~nm}$. Specifically for conifer species, we also

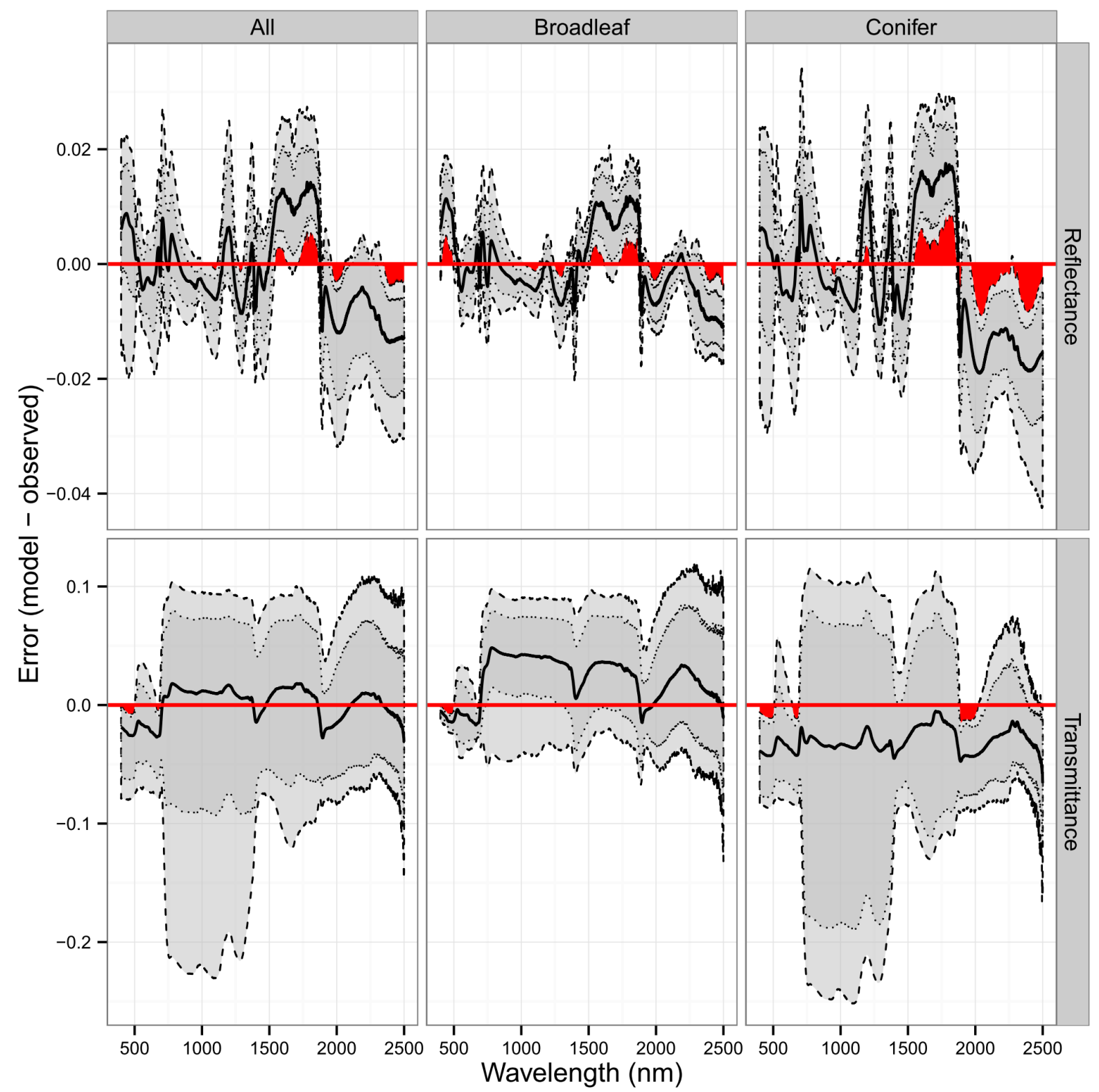

Figure 2 Bias in FFT simulated reflectance (top) and transmittance (bottom) spectra compared to measurements over all leaves (left) and only hardwood (middle) and conifer (right) species. For a given wavelength, the solid black line is the mean bias, the dark grey bounded by the dotted line is the $90 \%$ confidence interval, the light grey region bounded by the dashed line is the $95 \%$ confidence interval, the red line highlights a bias of 0 , and the red shaded regions highlight bias significant at the $95 \%$ confidence level. 
Table 3 Reflectance (Refl.) and transmittance (Tran.) spectral validation error statistics

366 aggregated across the visible $(400-800 \mathrm{~nm})$ and infrared $(801-2500 \mathrm{~nm})$ regions. Values from 367 other studies are included for comparison.

368

\begin{tabular}{|c|c|c|c|c|c|c|c|}
\hline & & \multicolumn{3}{|c|}{ Visible } & \multicolumn{3}{|c|}{ Infrared } \\
\hline & & RMSE & BIAS & SEPC & RMSE & BIAS & SEPC \\
\hline \multirow{7}{*}{ Refl. } & FFT All & 0.0083 & 0.0018 & 0.0071 & 0.0098 & -0.0020 & 0.0061 \\
\hline & --- Broadleaf & 0.0063 & 0.0023 & 0.0042 & 0.0064 & -0.0009 & 0.0034 \\
\hline & --- Conifer & 0.0101 & 0.0011 & 0.0090 & 0.0127 & -0.0035 & 0.0064 \\
\hline & Feret et al. (2008): CALMIT & 0.032 & 0.010 & 0.028 & --- & --- & --- \\
\hline & --- ANGERS & 0.019 & 0.001 & 0.019 & 0.016 & 0.003 & 0.014 \\
\hline & --- HAWAII & 0.021 & -0.008 & 0.020 & 0.036 & -0.031 & 0.017 \\
\hline & Di Vittorio (2009) & 0.0255 & 0.00477 & --- & --- & --- & --- \\
\hline \multirow{7}{*}{ Tran. } & FFT All & 0.0404 & -0.0133 & 0.0336 & 0.0551 & 0.0040 & 0.0537 \\
\hline & --- Broadleaf & 0.0248 & 0.0012 & 0.0167 & 0.0450 & 0.0266 & 0.0336 \\
\hline & --- Conifer & 0.0553 & -0.0346 & 0.0389 & 0.0661 & -0.0293 & 0.0566 \\
\hline & Feret et al. (2008): CALMIT & 0.029 & -0.005 & 0.025 & --- & --- & --- \\
\hline & --- ANGERS & 0.018 & -0.005 & 0.017 & 0.016 & 0.001 & 0.015 \\
\hline & --- HAWAII & 0.022 & 0.003 & 0.020 & 0.020 & -0.003 & 0.017 \\
\hline & Di Vittorio (2009) & 0.0442 & 0.0294 & --- & --- & --- & --- \\
\hline
\end{tabular}


Table 4 Error statistics for the comparison of inversion estimates of PROSPECT parameters $\mathrm{Cw}$ and $\mathrm{Cm}$ and measured values of equivalent water thickness (EWT) and leaf dry mass per unit area (LMA), respectively. Values from other inversion studies are included for comparison.

\begin{tabular}{|c|c|c|c|c|c|c|}
\hline & & RMSE & BIAS & SEPC & $\mathrm{CV}$ & $\mathrm{RMS} \% \mathrm{E}$ \\
\hline \multirow{7}{*}{$\begin{array}{c}\mathrm{Cw} / \mathrm{EWT} \\
\left(\mathrm{g} \mathrm{m}^{-2}\right)\end{array}$} & FFT Broadleaf & 17 & 5 & 16 & 18.8 & 21.64 \\
\hline & --- Conifer & 187 & 90 & 164 & 52.3 & 67.29 \\
\hline & Feret et al. (2008): LOPEX & 17 & -3 & 17 & 15.2 & --- \\
\hline & --- ANGERS & 20 & -1 & 20 & 17.1 & --- \\
\hline & --- HAWAII & 57 & -15 & 55 & 19.8 & --- \\
\hline & Feret et al. (2011): \#3 & 27 & --- & --- & --- & --- \\
\hline & Li \& Wang (2011) & 12 & 5 & --- & 20.10 & --- \\
\hline \multirow{7}{*}{$\begin{array}{c}\mathrm{Cm} / \mathrm{LMA} \\
\left(\mathrm{g} \mathrm{m}^{-2}\right)\end{array}$} & FFT Broadleaf & 20 & -18 & 9 & 24.5 & 43.75 \\
\hline & --- Conifer & 121 & 35 & 116 & 61.6 & 65.51 \\
\hline & Feret et al. (2008): LOPEX & 34 & 21 & 27 & 51.0 & --- \\
\hline & --- ANGERS & 26 & 1 & 26 & 49.8 & --- \\
\hline & --- HAWAII & 49 & -35 & 35 & 27.8 & --- \\
\hline & Feret et al. (2011): \#3 & 31 & --- & --- & --- & --- \\
\hline & Li \& Wang (2011) & 8 & -7 & --- & 13.75 & --- \\
\hline
\end{tabular}

\section{3.1.2. EWT and LMA}

374 Similar to the results of the spectral validation (section 3.1.1), the inversion estimates of

$375 \mathrm{Cw}$ and $\mathrm{Cm}$ (compared to measured values of EWT and LMA, respectively) displayed higher

376 accuracy for broadleaf $\left(\mathrm{CV}_{\mathrm{Cw}}=18.8 \%, \mathrm{CV}_{\mathrm{Cm}}=24.5 \%\right)$ versus conifer species $\left(\mathrm{CV}_{\mathrm{Cw}}=52.3 \%\right.$,

$\left.377 \mathrm{CV}_{\mathrm{Cm}}=63.3 \%\right)($ Table 4$)$. For the broadleaved species, our parameter estimates were within the

378 range observed previously (Table 4). While the inversion estimates for conifer species show a

379 lower performance compared to broadleaf trees, the error inversion results were primarily driven

380 by a single plant functional type - early successional conifers, which consisted entirely of pine

381 species (Pinus family). Notably, a few estimates for mid-successional conifer species displayed 
382 significant divergence with observations, but in general fell along the 1:1 relationship (Figures 3

383 and 4).
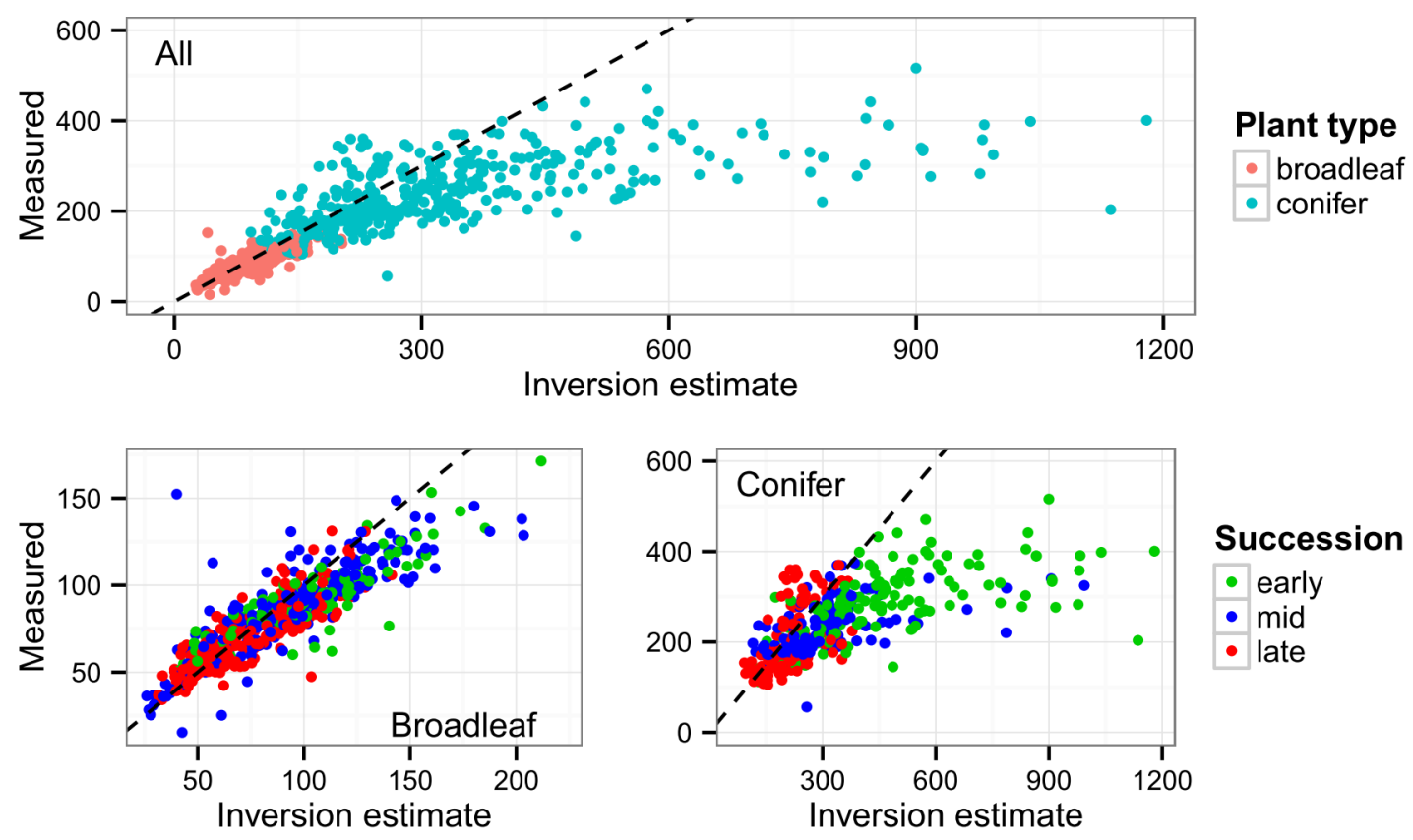

385 Figure 3 Modeled and observed equivalent water thickness $\left(\mathrm{g} \mathrm{m}^{-2}\right)$ for both conifers and 386 hardwoods (a), just hardwoods (b), and just conifers (c). Point colors indicate plant type (a) or 387 successional stage $(b, c)$. The dashed line represents a 1:1 fit. 

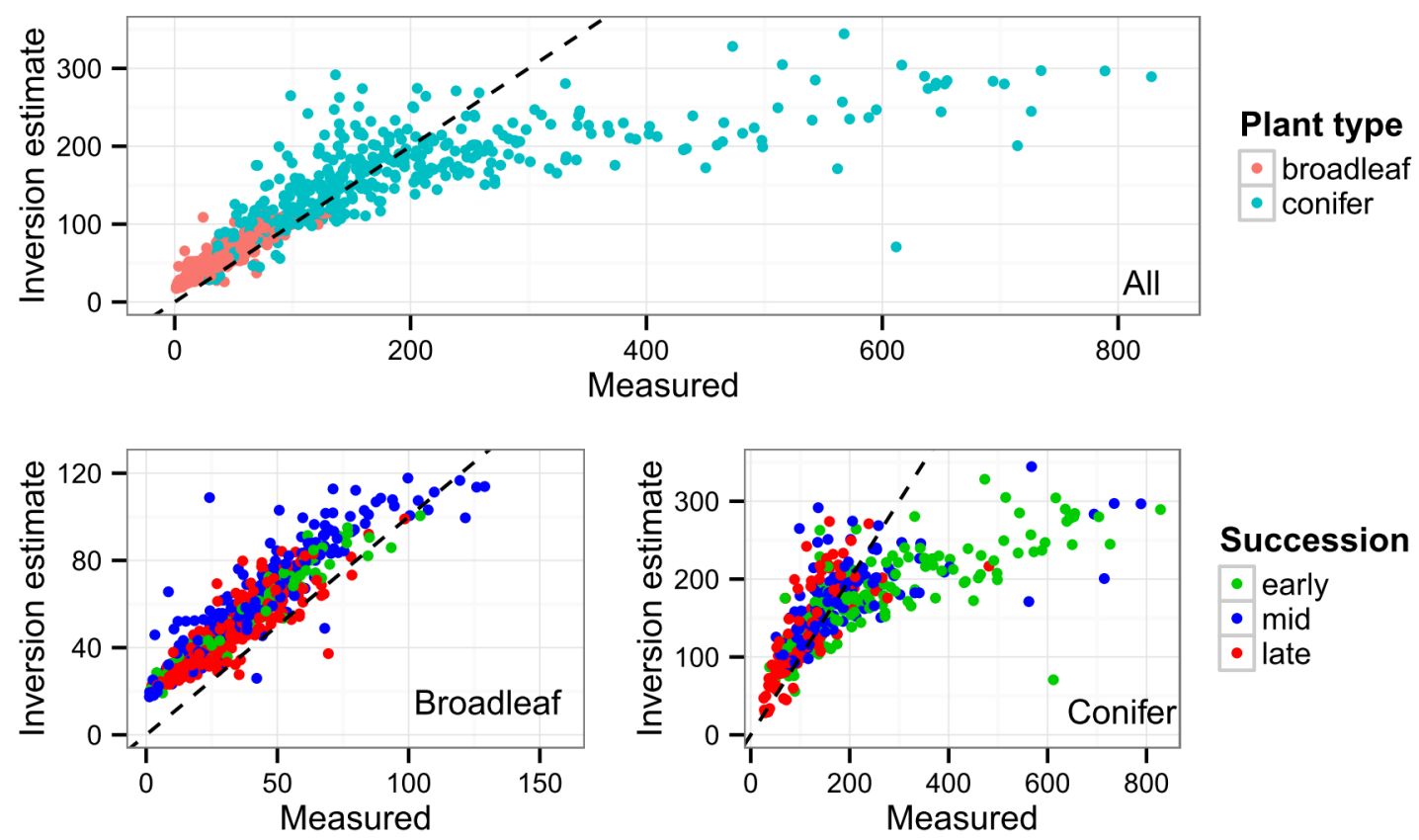

391 Figure 4 Modeled and observed leaf dry mass per unit area $\left(\mathrm{g} \mathrm{m}^{-2}\right)$ for both conifers and 392 hardwoods (a), just hardwoods (b), and just conifers (c). Point colors indicate plant type (a) or 393 successional stage $(\mathrm{b}, \mathrm{c})$. The dashed line represents a 1:1 fit.

\section{3.2. Sensor simulation experiment}

\section{3.2.1. Parameter Error}

Across all of the selected sensors, the highest PROSPECT 5 parameter inversion

397 uncertainty and bias were observed for Car (Figure 5, Table 5). This can readily be explained by

398 the Car specific absorption feature, which is both extremely narrow and overlaps substantially

399 with that of Cab (Figure S1). On the other extreme, the most accurate and least uncertain

400 retrieved parameter was $\mathrm{N}$, which is related to the reflectivity of the leaf across the entire

401 spectrum (Figure 5, Table 5, Figure S1). Despite relatively narrow absorption features, most

402 simulated sensors were able to retrieve Cab with reasonably good accuracy, which is not

403 surprising given the long history of monitoring vegetation pigmentation using various platforms.

404 Similarly, all sensors except CHRIS-Proba and AVHRR retrieved Cw with low uncertainty and 
405 bias, reflecting the wide and strong absorption features of water in the NIR and SWIR (Figure 5,

406 Table 5, Figure S1). The failure of CHRIS-Proba to retrieve $\mathrm{Cw}$ can be attributed to its inability

407 to measure in this spectral range (Figure S4). The retrieval accuracy for $\mathrm{Cm}$ was much more

408 sensor dependent, with good performance among the simulated hyperspectral sensors, VIIRS,

409 and Landsat 8, followed by lower performance for simulated Landsat 5 and 7 and MODIS, and a

410 poor result for the simulated Chris-PROBA and AVHRR data (Figure 5, Table 5). Although the

411 specific absorption feature for $\mathrm{Cm}$ is very wide, the sensitivity of reflectance to $\mathrm{Cm}$ values is

412 much lower than for other parameters and almost the entire feature can be masked or confounded

413 by $\mathrm{Cw}$ (Figure $\mathrm{S} 1$ ). This suggests that $\mathrm{Cm}$ is very dependent on precise locations of certain bands

414 and therefore explains the differences in the estimate accuracy of apparently similar sensors like

415 Landsat 5, 7, and 8 (Table 2, Figure S4). More generally, the importance of precise band widths

416 and locations is evidenced by the noticeably better performance of Landsat 8 compared to

417 Landsat 5 and 7 for certain parameters (Figure 5, Table 5) despite the subtle differences in the

418 sensors' respective bandwidths (Table 2, Figure S4).

419 Table 5 Uncertainty and relative bias in parameter estimates from inversion of simulated spectra 420 filtered through relative spectral response curves of different sensors.

\begin{tabular}{ccccccccccc}
\multicolumn{9}{c}{ Uncertainty $(\pi)$} & \multicolumn{5}{c}{ Relative bias $(\alpha)$} \\
Sensor & $\mathrm{N}$ & $\mathrm{Cab}$ & $\mathrm{Car}$ & $\mathrm{CW}$ & $\mathrm{Cm}$ & $\mathrm{N}$ & $\mathrm{Cab}$ & $\mathrm{Car}$ & $\mathrm{Cw}$ & $\mathrm{Cm}$ \\
\hline ASD Field Spec & 0.20 & 0.54 & 2.91 & 0.26 & 1.33 & -0.001 & 0.05 & 0.08 & 0.01 & -0.05 \\
AVIRIS NG & 0.87 & 2.36 & 12.78 & 1.12 & 5.81 & -0.004 & 0.05 & -0.03 & 0.004 & -0.03 \\
AVIRIS Classic & 1.62 & 4.61 & 26.06 & 2.13 & 11.02 & -0.04 & 0.06 & -0.44 & -0.01 & -0.08 \\
Hyperion & 1.69 & 4.81 & 27.35 & 2.23 & 11.44 & -0.04 & 0.05 & -0.49 & -0.02 & -0.06 \\
CHRIS-Proba & 21.93 & 20.77 & 53.86 & 106.5 & 173.8 & -0.71 & -0.50 & -2.52 & 2.41 & 87.84 \\
Landsat 5 & 8.90 & 17.14 & 114.8 & 13.32 & 66.43 & -1.53 & -0.64 & -5.16 & -0.76 & -0.89 \\
Landsat 7 & 8.84 & 21.90 & 134.2 & 12.94 & 66.07 & -1.52 & 0.55 & -9.17 & -0.77 & -0.91 \\
Landsat 8 & 4.31 & 12.23 & 118.5 & 11.05 & 27.99 & -0.33 & 0.28 & -3.02 & -0.32 & -0.005 \\
MODIS & 10.29 & 15.99 & 220.5 & 16.65 & 86.00 & -1.20 & 0.07 & -29.14 & -1.88 & 5.43 \\
VIIRS & 2.49 & 13.24 & 174.4 & 4.75 & 18.23 & -0.09 & 1.57 & -18.06 & -0.09 & 0.004 \\
AVHRR & 25.47 & 114.2 & 263.3 & 74.58 & 179.1 & -0.26 & -7.47 & -39.04 & -8.04 & 77.21
\end{tabular}




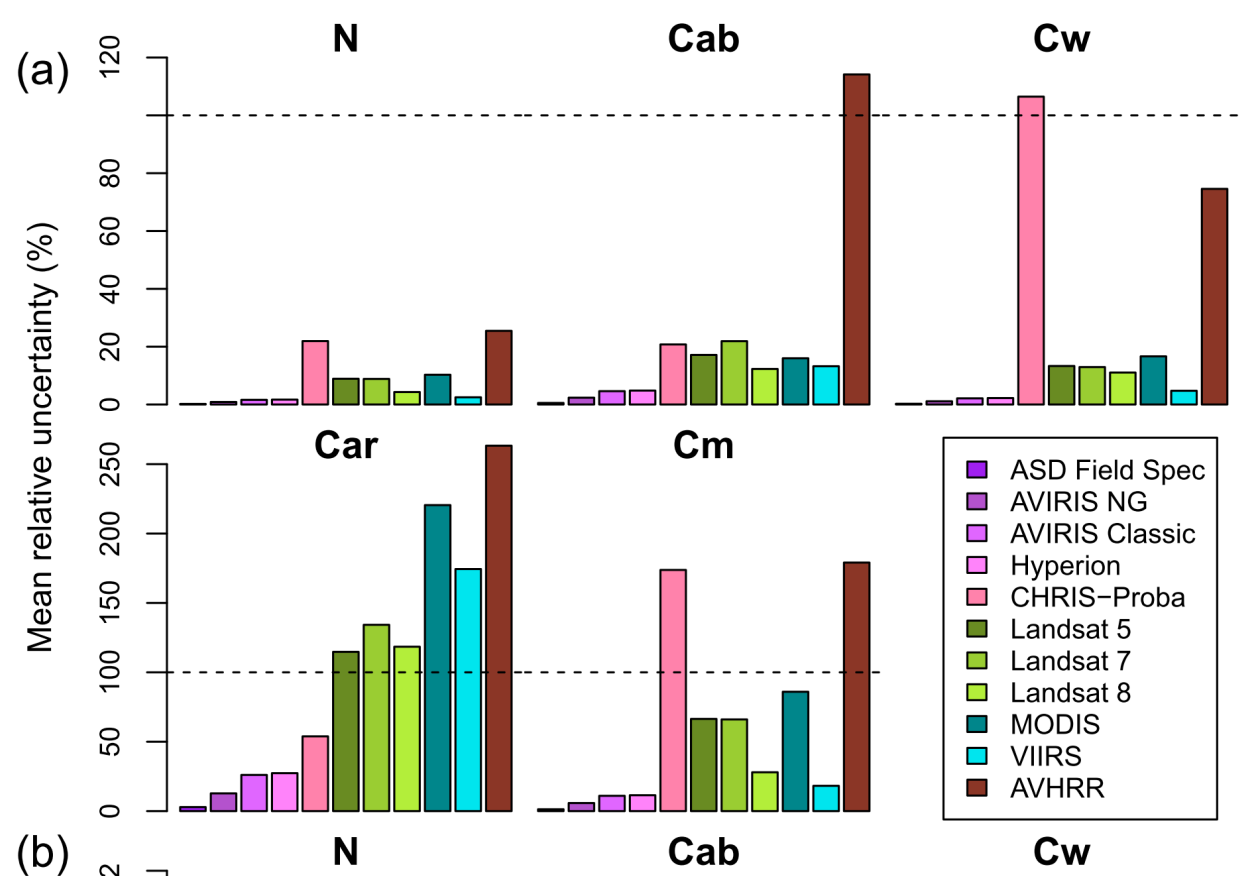

(b)

N

Cab

Cw

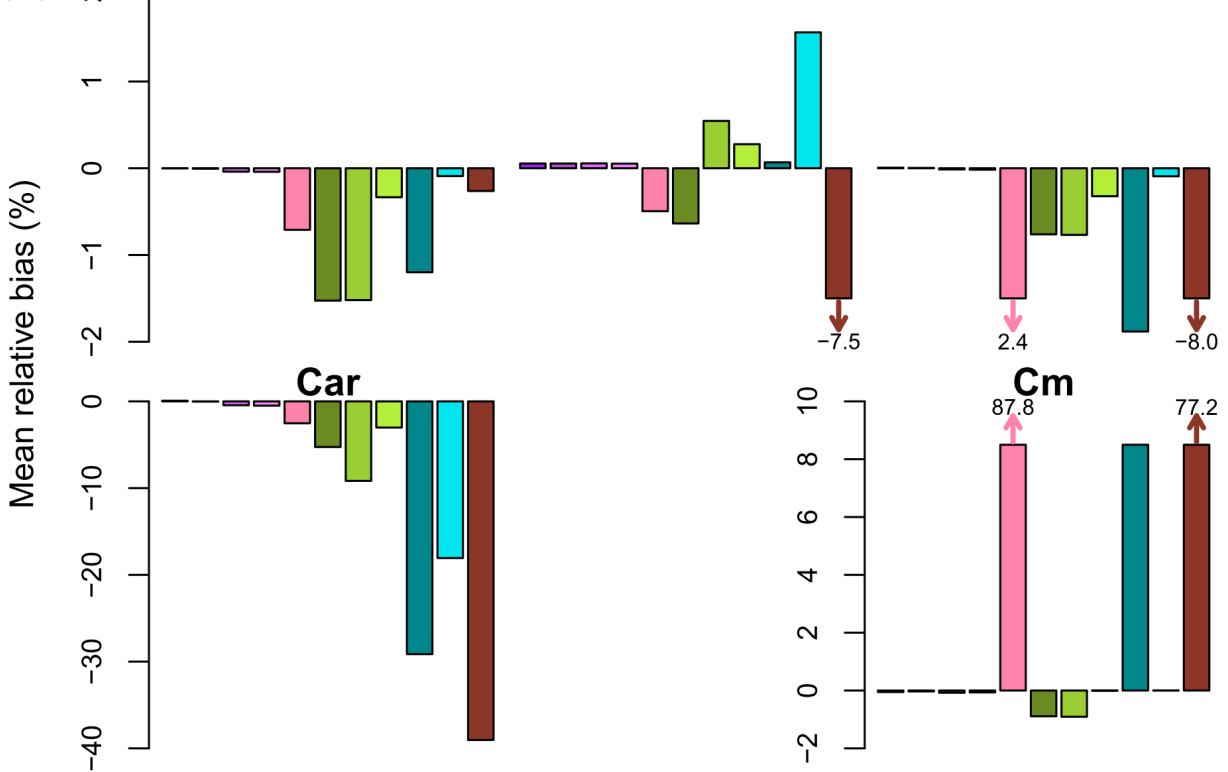

Figure 5 Mean uncertainty (a) and relative bias (b) (as defined in section 2.3) of inversion estimates for each parameter and simulated sensor. Sensors are arranged along the $\mathrm{x}$-axis in approximate order of increasing spectral resolution.

\subsubsection{Parameter Uncertainty and Covariance}

Figure 6 shows an example of processed inversion output based on the high spectral

resolution field spectrometer data and the spectral response functions of AVIRIS NG, Landsat 8, and MODIS. All four plots are simulated from a single set of parameters, so differences in results 
430 are caused only by variations in spectral measurement characteristics (Figure S4). Out of these

431 four sensors, the uncertainties increase with approximately decreasing spectral resolution, with

432 lowest uncertainties in the full spectra, second-lowest for AVIRIS NG, second highest for

433 Landsat 8, and highest for MODIS. The shapes of parameter covariances are distinctly different

434 between these sensors, reflecting differences in the ability of the inversion to distinguish between

435 parameters based on the available information. Across all four sensors, we observe strong

436 positive covariance between $\mathrm{N}$ and $\mathrm{Cm}$, since these parameters influence wide regions of the

437 reflectance spectrum in opposite ways (Figure S1). Similarly, we also observe a positive

438 covariance between $\mathrm{N}$ and $\mathrm{Cab}$, although the strength of this covariance is not equal across

439 sensors. The remaining covariances are mostly specific to MODIS, whose band configuration

440 increases the overlap between the associated parameters (Figure S4).

441

We find that inversion estimates for the field spectra are occasionally falsely

443 overconfident. For instance, the true value of $\mathrm{N}$ and $\mathrm{Cw}$ is outside the $95 \%$ confidence limit of

444 their estimated joint probability distribution at full, field spectrometer resolution. That being

445 said, this is less of an issue for the other sensors, where the joint probability distribution

446 encompasses the true value. This suggests that spectral resolution below $5 \mathrm{~nm}$ may not provide

447 additional information content, particularly for the broad absorption features within leaves,

448 because of the strong autocorrelation between adjacent wavelengths. More importantly, although

449 the joint posterior probability distributions from Landsat 8 and MODIS appear wide, the

450 resulting parameter values are constrained by an order of magnitude or more compared to the

451 priors. 

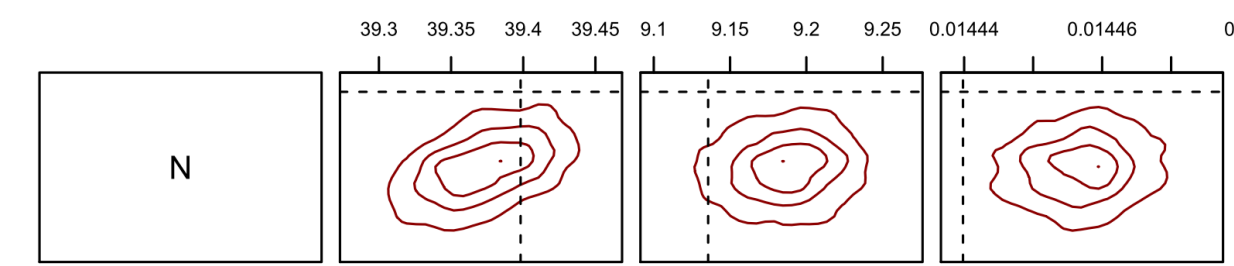

$0.01214 \quad 0.01218 \quad 0.01222$
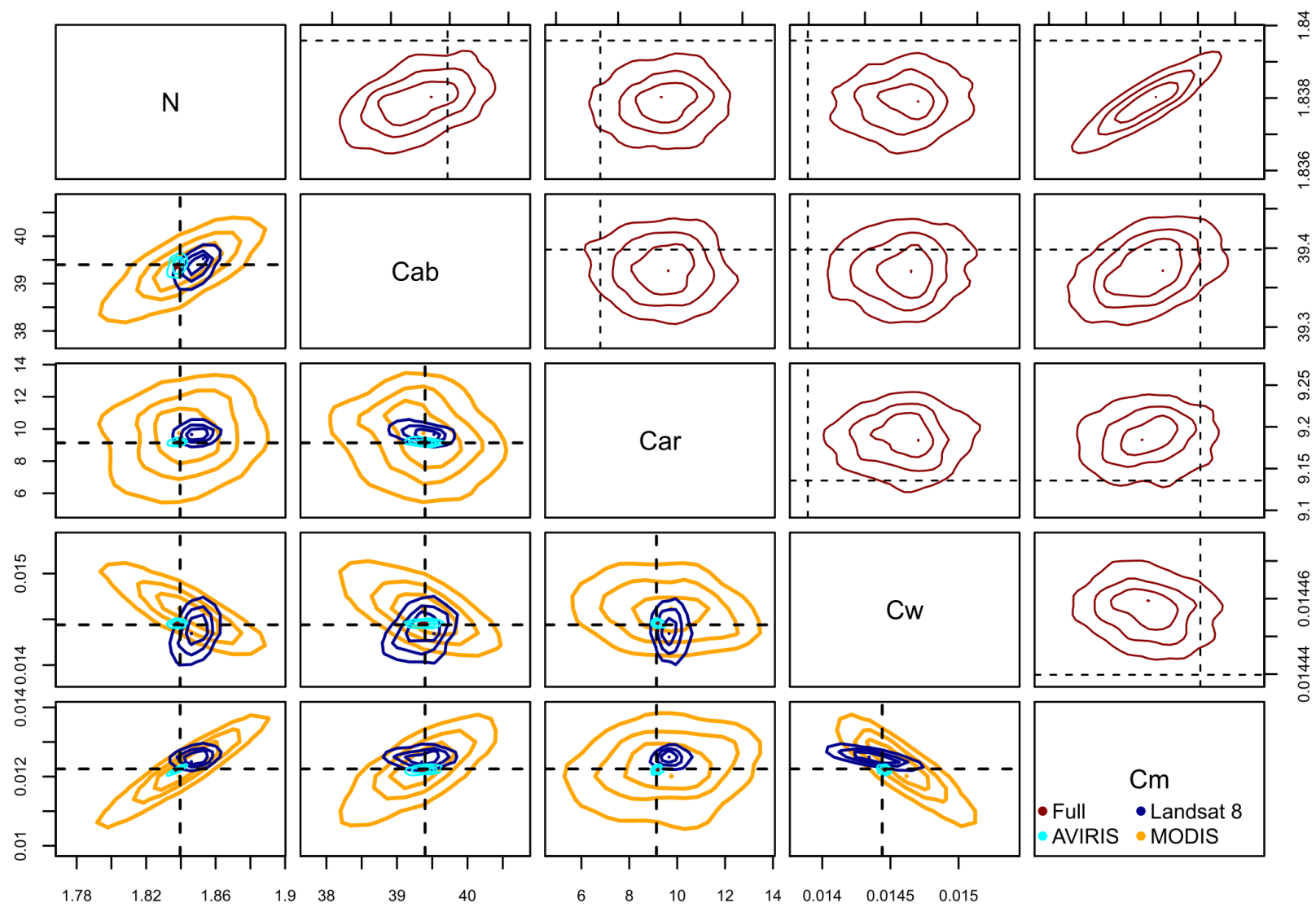

Figure 6 Example joint probability distribution for parameter inversion estimates of simulated spectra using the full spectra (red; top panels) and the relative spectral response (RSR) functions of AVIRIS NG (cyan), Landsat 8 (dark blue), and MODIS (orange). Dotted lines indicate true parameter values. Note that the axis range of the top panels is substantially smaller than that of the bottom panels.

\section{Discussion}

In this manuscript, we reiterate the power of the Bayesian RTM inversion framework for using spectral data to characterize vegetation and monitor ecosystem dynamics. The use of a physically-based model to describe the interaction of light with different vegetation structural

462 and biochemical components improves the extent to which such an approach can be generalized

463 across vegetation types and sub-orbital and spaceborne platforms compared to more empirical

464 approaches. Moreover, this physically-based approach enables estimation of vegetation

465 properties from sensors of varying spectral resolution, and our ability to quantify uncertainty in 
466 our estimates provides the versatility to assess the performance of various sensors for a range of 467 applications.

468 Our inversion results are comparable to other studies (Feret et al. 2008, 2011; Li \& Wang 469 2011; Di Vittorio et al. 2009a). The results outperformed those of Feret et al. (2011) despite the 470 fact that we performed the inversion on measured spectra and inverted all five PROSPECT

471 parameters, whereas Feret et al. (2011) performed inversions on synthetic spectra and did not 472 attempt to estimate the structure parameter N. As such, we suggest that our approach does not 473 come at the cost of model performance, and, importantly, enables the use of a much wider range 474 of spectral data to explore vegetation dynamics. Our method contrasts with some previous 475 methods (e.g. Feret et al. 2008, 2011) that utilize both reflectance and transmittance observations 476 to invert leaf models such as PROSPECT. These require the use of additional, expensive 477 instruments, such as an integrating sphere, that typically introduce significant noise and potential 478 errors in the measurements given their inadequate design across a range of leaf habits. In 479 addition, our approach suggests the possibility to instead use leaf reflectance observations alone 480 to scale canopy-scale RTMs by coupling measured reflectance with simulated transmittance.

481 Placed in the context of past inversion studies, our work reveals some continuing 482 challenges in the use of PROSPECT to model leaf optical properties and provides some guidance 483 for future RTM development. For instance, we noted issues with using PROSPECT to model 484 reflectance and transmittance in the 400 to $500 \mathrm{~nm}$ range (Figure 2) that have also been reported 485 in previous studies. Feret et al. (2008) observed a consistently negative transmittance bias and 486 occasionally a positive or negative reflectance bias. Similarly, Croft et al. (2013) report 487 systematic underestimates of reflectance in this part of the spectrum. One possible source of bias 488 is PROSPECT's simplified description of leaf structure (Jacquemoud and Baret 1990) and failure 
to account for specular reflectance off the leaf surface (Grant 1987). Another possible source of

490 error is imprecise calibration of the leaf refractive index, which has a relatively strong

491 wavelength dependence in the region of interest (400-500 nm) (Feret et al. 2008). Alternatively,

492 this bias could be the result of the failure of the PROSPECT 5 model to properly represent the

493 spectral properties of chlorophyll in leaves, potentially requiring additional calibration across a

494 broader range of species and environments. The common specific absorption feature for

495 chlorophyll $a$ and $b\left(k_{C a b}(\lambda)\right)$ in PROSPECT 5 used in this study is empirically calibrated to a

496 single data set (ANGERS; Feret et al. 2008), and many studies have shown that this feature may

497 need to be re-calibrated to the data at hand to obtain accurate inversion estimates, particularly for

498 species dissimilar to those in the ANGERS data set (Malenovský et al. 2006; Moorthy et al.

499 2008; Zhang et al. 2008; Li \& Wang 2013). As well, PROSPECT 5 fails to distinguish between

500 chlorophyll $a$ and $b$, which have overlapping but distinctly different absorption signatures and

501 whose ratios have been shown to be affected by environmental conditions (Blackburn 2007; Di

502 Vittorio 2009b; Di Vittorio \& Biging 2009). Fortunately, it has been shown that not only can

503 chlorophyll $a$ and $b$ be distinguished using imaging spectroscopy (Di Vittorio 2009b), but that

504 these differences can be incorporated into a RTM to improve its performance (Di Vittorio

505 2009a).

506 Reflectance in the SWIR region $(>1500 \mathrm{~nm})$ - where we observed significant reflectance

507 bias (Figure 2) - is influenced by three PROSPECT parameters: N, Cw, and Cm (Figure S1). All

508 three parameters modulate reflectance in this spectral region monotonically: Reflectance

509 increases with higher values of $\mathrm{N}$ and decreases with higher values of $\mathrm{Cw}$ and $\mathrm{Cm}$ (Figure S1).

510 This means that it is unlikely that incorrect parameter trade-off within the algorithm (e.g.

511 preferentially selecting $\mathrm{Cw}$ over $\mathrm{Cm}$ ) could contribute to this error. Feret et al. (2008) also 
512 reported similar reflectance bias patterns for the ANGERS data set despite using a different

513 inversion methodology. We hypothesize this bias is the result of PROSPECT's insufficient

514 characterization of the specific absorption spectrum of leaf dry matter $\left(k_{C m}(\lambda)\right)$, since the

515 absorption characteristics of water $\left(k_{C w}(\lambda)\right)$ are very well known and $\mathrm{N}$ is not dependent on an

516 absorption feature. This would also help explain the negative bias we observed between spectral

517 inversion estimates of $\mathrm{Cm}$ and direct measurements of LMA (Figure 3, Table 3). Other studies

518 have also reported a bias but the direction of this bias has not been consistent, with some studies

519 showing negative bias across all their data (Li \& Wang 2011; Cheng et al. 2014) and others

520 reporting a bias whose magnitude and direction is data-dependent (Feret et al. 2008). This may

521 partially be explained by the simple treatment of non-pigment compounds in the current

522 PROSPECT model, wherein protein, cellulose, hemicellulose, sugar, starch, and lignin are

523 aggregated into a single parameter (Cm) (Fourty et al. 1996). As with chlorophyll, the absorption

524 feature for Cm is empirically derived (Feret et al. 2008) and fails to represent variability in the

525 relative abundance of the different components (Poorter et al. 2009). Fortunately, Wang et al.

526 (2015) demonstrated that, with proper calibration, it is possible to use PROSPECT inversion to

527 determine leaf protein as well as combined cellulose and lignin content. Furthermore,

528 measurements of LMA are an aggregate of a number of constituents including chlorophyll,

529 carotenoids, lipids, organic acids, phenolics, and vascular tissue (Poorter et al. 2009), which

530 would positively bias the measurement compared to the spectral estimate. Finally, it is possible

531 that strong positive covariance between $\mathrm{N}$ and $\mathrm{Cm}$ (Figure 6) caused by their significant spectral

532 overlap (Figure S1) interferes with accurate estimation of $\mathrm{Cm}$. However, based on our finding

533 that inversions of simulated spectra did not display this problem (Field spectra in Figure 5;

534 Figure S6), we conclude the error is in fact driven more by model formulation than by parameter 
535 identifiability. We are aware of only one other study that attempted to estimate all five

536 PROSPECT parameters (including the structure parameter, N) simultaneously: Li \& Wang

537 (2011) presented a novel algorithm for PROSPECT inversion that assigns a separate merit

538 function to each parameter (rather than a single common merit function for all parameters) and

539 demonstrated its improved performance over traditional approaches. However, although their

540 new algorithm reduced error and bias in the LMA estimates, a negative bias comparable to the

541 one we report still remained across all of their data sets.

542 Based on these results, we suggest that future PROSPECT development should aim for

543 finer distinction in leaf chemical components. That being said, the introduction of additional

544 parameters into a model must be approached with caution, as parameter precision and

545 identifiability tend to decrease with model complexity. The ability of our Bayesian inversion to

546 quantify parameter uncertainty and covariance makes it useful for nested model selection. An

547 alternative approach to addressing the issue of empirically-calibrated absorption coefficients is to

548 explicitly account for their uncertainty and covariance structures. Within our Bayesian

549 framework, such uncertainties could be treated as observation errors and propagated to the

550 uncertainty in parameter estimates. In subsequent work, we will explore such a calibration using

551 coupled spectral-trait data from multiple available datasets.

552 The relatively large magnitude in our observed transmittance bias (compared to

553 reflectance) is likely the result of using only reflectance as input in our inversion. A combined

554 approach using measured reflectance and transmittance observations, collected on the same leaf

555 samples, may have shown the variability distributed more evenly because the minimization of

556 the residuals would have been more balanced between the two vectors of data. Ultimately, higher

557 uncertainties in transmittance estimates compared to reflectance are a consequence of the 
558 inherent challenges in using integrating spheres to measure transmittance, especially the

559 substantial noise in the SWIR regions. This is supported by the absence of significant systematic

560 bias between measured and modeled transmittance across the overwhelming majority of the

561 spectrum (Figure 2). Moreover, although the confidence intervals on transmittance bias are as

562 high as $25 \%$ at some wavelengths, averaging over all spectra and aggregating across the visible

563 (400 to $800 \mathrm{~nm}$ ) and infrared (801 to $2500 \mathrm{~nm}$ ) regions leads to results similar to those reported

564 in other field spectra inversion studies, even though these studies used both reflectance and

565 transmittance as input (Table S1). Although our overall transmittance RMSE values were two to

566 three times higher than those reported by Feret et al. (2008), these errors are inflated by the

567 inclusion of conifer species, for which reflectance is harder to measure reliably and the

568 assumptions of the PROSPECT model are not satisfied (Jacquemoud \& Baret 1990; Di Vittorio

569 2009a; Allen et al. 1969). As well, measurements of needle-leaf transmittance often result in

570 considerable noise in longer wavelengths (SWIR, $>2000 \mathrm{~nm}$ ) given the physical challenges of

571 making these measurements on needle-leaf species (and other leaf types), generally poor lamp

572 performance as compared to other methods, and the much smaller transmission of light in these

573 wavelengths (often resulting in signals below the precision of the instrument). As such we

574 would expect higher reported error compared to other leaf morphologies. For example, in

575 examining our broadleaf samples we observed that the statistics for transmittance are much

576 closer to those reported by Feret et al. (2008), despite not including measured transmittance in

577 the inversion (Table S1). Our transmittance error statistics are also similar to those reported for

578 conifers by Di Vittorio (2009a) who used transmittance information and a re-calibrated version

579 of the LIBERTY leaf RTM (Table 3). Moreover, our reflectance statistics show error comparable

580 to or lower than those reported in similar studies (Feret et al. 2008; Di Vittorio 2009a). 
Through our sensor experiment, we explicitly demonstrate the tradeoffs between spectral

582 information content and parameter uncertainty and identifiability. With increasingly coarse

583 spectral resolution, we observed not only wider parameter confidence intervals indicating higher

584 uncertainty but also tighter covariance structures indicating a reduced ability to distinguish

585 between parameters (Figure 6). This comparison approach can be used to guide future

586 enhancements of radiative transfer models by quantitatively showing whether a model of a given

587 complexity is warranted given data of a particular quality. For example, in our simulation

588 experiment, all the full-range hyperspectral sensors were capable of accurately estimating

589 chlorophyll and carotenoids, but the ability of multispectral sensors to do so was dramatically

590 lower (Figures 5, S6, and S7; Table 5). We therefore can conclude that the use of PROSPECT 5

591 is warranted when performing inversion of hyperspectral data, but PROSPECT 4 (which does

592 not distinguish between pigments) may be preferable for multispectral data. A similar framework

593 can be used to determine the utility of increasingly complex future versions of PROSPECT that

594 further differentiate leaf biochemical and structural components.

595 Importantly, the results of our sensor simulation experiment are highly idealized due to

596 their failure to consider canopy structure, atmospheric effects, sun-sensor geometry, and sensor

597 radiometric and spatial characteristics. However, a similar Bayesian inversion framework has

598 been shown to work on MODIS data for the related coupled leaf-canopy RTM PROSAIL (Zhang

599 et al. 2005, 2006, 2009, \& 2012) and we believe the framework can be readily applied to other

600 RTMs that address many of the limitations of our study. In future work, we will explore

601 Bayesian spectral inversion of the coupled leaf-canopy RTM responsible for energy balance

602 calculations in the ED2 ecosystem model (Medvigy et al. 2009) on atmospherically corrected

603 and orthorectified AVIRIS imagery, which will be an important milestone in bringing together 
604 the remote sensing and ecological modeling communities. In the long run, our framework could

605 also be extended to the inversion of coupled canopy-atmosphere models using a combination of

606 meteorological and spectral data from Earth Observation satellites, leveraging the relative

607 advantages of each platform to generate unified time series of ecologically meaningful

608 parameters with unprecedented spatial and temporal resolution.

\section{5. Conclusions}

610 This study introduces a novel application of Bayesian spectral inversion to the

611 PROSPECT 5 leaf RTM that explicitly takes into account uncertainty and correlation in

612 parameter estimates. Validation of our algorithm on a coupled leaf spectral-trait database

613 revealed accuracy comparable to previous inversion algorithms despite only using reflectance

614 observations and the default PROSPECT model (i.e. no additional refinement of the specific

615 absorption features). By simulating reflectance measurements with the spectral characteristics of

616 different remote sensing platforms, we were able to quantify the relationship between spectral

617 resolution and parameter uncertainty. Although our simulated observations are highly idealized,

618 we believe the resulting patterns in retrieved parameter accuracy and precision are representative

619 of the advantages and limitations of the spectral configurations of different sensors for remote

620 sensing of vegetation. Our work reinforces the notion that Bayesian spectral inversion provides a

621 powerful and versatile framework for future RTM development and single- and multi-

622 instrumental remote sensing of vegetation, and we encourage members of the remote sensing

623 community to apply and build upon the tools we have developed (which can be viewed and

624 downloaded at https://github.com/PecanProject/pecan/tree/master/modules/rtm). 


\section{6. Acknowledgements}

626 This work is supported by NASA Grant NNX14AH65G and the Boston University Department

627 of Earth \& Environment. Field data collection was supported by NASA Grant NNX08AN31. We

628 would also like to thank Sarah Weiskopf, Afshin Pourmokhtarian, Elizabeth Cowdery, Joshua

629 Mantooth, and especially Christine Rollinson for their generous feedback on the content, style, 630 and organization of this paper.

631 


\section{References}

633 Allen, W. A., Gausman, H. W., Richardson, A. J., \& Thomas, J. R. (1969). Interaction of Isotropic Light with a Compact Plant Leaf. Journal of the Optical Society of America, 59(10), 11-14.

Asner, G. P., Martin, R. E., Anderson, C. B., \& Knapp, D. E. (2015). Quantifying forest canopy traits: Imaging spectroscopy versus field survey. Remote Sensing of Environment, 158, 1527. http://doi.org/10.1016/j.rse.2014.11.011

Atzberger, C., \& Richter, K. (2012). Spatially constrained inversion of radiative transfer models

Blackburn, G. A. (2007). Hyperspectral remote sensing of plant pigments. Journal of Experimental Botany, 58(4), 855-867. http://doi.org/10.1093/jxb/erl123

Blackburn, G. A., \& Ferwerda, J. G. (2008). Retrieval of chlorophyll concentration from leaf reflectance spectra using wavelet analysis. Remote Sensing of Environment, 112(4), 16141632. http://doi.org/10.1016/j.rse.2007.08.005

Bousquet, L., Lachérade, S., Jacquemoud, S., \& Moya, I. (2005). Leaf BRDF measurements and model for specular and diffuse components differentiation. Remote Sensing of Environment, 98(2-3), 201-211. http://doi.org/10.1016/j.rse.2005.07.005

Cheng, T., Rivard, B., Sánchez-Azofeifa, A. G., Féret, J. B., Jacquemoud, S., \& Ustin, S. L. (2014). Deriving leaf mass per area (LMA) from foliar reflectance across a variety of plant species using continuous wavelet analysis. ISPRS Journal of Photogrammetry and Remote Sensing, 87, 28-38. http://doi.org/10.1016/j.isprsjprs.2013.10.009

Cheng, T., Rivard, B., Sánchez-Azofeifa, G. A., Feng, J., \& Calvo-Polanco, M. (2010). Continuous wavelet analysis for the detection of green attack damage due to mountain pine beetle infestation. Remote Sensing of Environment, 114(4), 899-910. http://doi.org/10.1016/j.rse.2009.12.005

Combal, B., Baret, F., Weiss, M., Trubuil, A., Macé, D., Pragnère, A., Myneni, R.B., Knyazikhin, Y., \& Wang, L. (2003). Retrieval of canopy biophysical variables from 
bidirectional reflectance using prior information to solve the ill-posed inverse problem. Remote Sensing of Environment, 84(1), 1-15. http://doi.org/10.1016/S0034-4257(02)000354

Couture, J. J., Serbin, S. P., \& Townsend, P. A. (2013). Spectroscopic sensitivity of real-time, rapidly induced phytochemical change in response to damage. New Phytologist, 198(1), 311-319. http://doi.org/10.1111/nph.12159

Cressie, N., Calder, C. A., Clark, J. S., Ver Hoef, J. M., \& Wikle, C. K. (2009). Accounting for uncertainty in ecological analysis: The strengths and limitations of hierarchical statistical modeling. Ecological Applications, 19(3), 553-570. http://doi.org/10.1890/07-0744.1

Croft, H., Chen, J. M., \& Zhang, Y. (2014). The applicability of empirical vegetation indices for determining leaf chlorophyll content over different leaf and canopy structures. Ecological Complexity, 17(1), 119-130. http://doi.org/10.1016/j.ecocom.2013.11.005

Croft, H., Chen, J. M., Zhang, Y., \& Simic, A. (2013). Modelling leaf chlorophyll content in broadleaf and needle leaf canopies from ground, CASI, Landsat TM 5 and MERIS reflectance data. Remote Sensing of Environment, 133, 128-140. http://doi.org/10.1016/j.rse.2013.02.006

Dawson, T. P., Curran, P. J., \& Plummer, S. E. (1998). LIBERTY - Modeling the effects of Leaf Biochemical Concentration on Reflectance Spectra. Remote Sensing of Environment, 65(1), 50-60. http://doi.org/10.1016/S0034-4257(98)00007-8

Deel, L. N., McNeil, B. E., Curtis, P. G., Serbin, S. P., Singh, A., Eshleman, K. N., \& Townsend, P. a. (2012). Relationship of a Landsat cumulative disturbance index to canopy nitrogen and forest structure. Remote Sensing of Environment, 118, 40-49. http://doi.org/10.1016/j.rse.2011.10.026

Di Vittorio, A. V. (2009a). Enhancing a leaf radiative transfer model to estimate concentrations and in vivo specific absorption coefficients of total carotenoids and chlorophylls a and $\mathrm{b}$ from single-needle reflectance and transmittance. Remote Sensing of Environment, 113(9), 1948-1966. http://doi.org/10.1016/j.rse.2009.05.002

Di Vittorio, A. V. (2009b). Pigment-based identification of ozone-damaged pine needles as a basis for spectral segregation of needle conditions. Journal of Environmental Quality, 38(3), 855-67. http://doi.org/10.2134/jeq2008.0260

Di Vittorio, A. V., \& Biging, G. S. (2009). Spectral identification of ozone-damaged pine needles. International Journal of Remote Sensing, 30(12), 3041-3073. http://doi.org/10.1080/01431160802558725

Dietze, M. C., Lebauer, D. S., \& Kooper, R. (2013). On improving the communication between models and data. Plant, Cell and Environment, 36(9), 1575-1585. http://doi.org/10.1111/pce.12043 
Dietze, M. C., \& Moorcroft, P. R. (2011). Tree mortality in the eastern and central United States: Patterns and drivers. Global Change Biology, 17(11), 3312-3326. http://doi.org/10.1111/j.1365-2486.2011.02477.x

Elsaesser, G. S., \& Kummerow, C. D. (2015). The Sensitivity of Rainfall Estimation to Error Assumptions in a Bayesian Passive Microwave Retrieval Algorithm. Journal of Applied Meteorology and Climatology, 54(2), 408-422. http://doi.org/10.1175/JAMC-D-14-0105.1

Fassnacht, F. E., Stenzel, S., \& Gitelson, A. A. (2015). Non-destructive estimation of foliar carotenoid content of tree species using merged vegetation indices. Journal of Plant Physiology, 176, 210-217. http://doi.org/10.1016/j.jplph.2014.11.003

Feret, J. B., François, C., Asner, G. P., Gitelson, A. A., Martin, R. E., Bidel, L. P. R., Ustin, S. L. , le Maire, G., \& Jacquemoud, S. (2008). PROSPECT-4 and 5: Advances in the leaf optical properties model separating photosynthetic pigments. Remote Sensing of Environment, 112(6), 3030-3043. http://doi.org/10.1016/j.rse.2008.02.012

Féret, J.-B., François, C., Gitelson, A., Asner, G. P., Barry, K. M., Panigada, C., Richardson, A. D., \& Jacquemoud, S. (2011). Optimizing spectral indices and chemometric analysis of leaf chemical properties using radiative transfer modeling. Remote Sensing of Environment, 115(10), 2742-2750. http://doi.org/10.1016/j.rse.2011.06.016

Ferreira, M. P., Grondona, A. E. B., Rolim, S. B. A., \& Shimabukuro, Y. E. (2013). Analyzing the spectral variability of tropical tree species using hyperspectral feature selection and leaf optical modeling. Journal of Applied Remote Sensing, 7(1), 073502. http://doi.org/10.1117/1.JRS.7.073502

Fourty, T., Baret, F., Jacquemoud, S., Schmuck, G., \& Verdebout, J. (1996). Leaf optical properties with explicit description of its biochemical composition: Direct and inverse problems. Remote Sensing of Environment, 56(2), 104-117. http://doi.org/10.1016/00344257(95)00234-0

Friedl, M. A., McIver, D. K., Hodges, J. C. F., Zhang, X., Muchoney, D., Strahler, A. H., Woodcock, C. E., Gopal, S., Schneider, A., Cooper, A., Baccini, A., Gao, F., \& Schaaf, C. (2002). Global land cover mapping from MODIS: algorithms and early results. Remote Sensing Of Environment, 83, 287-302. http://doi.org/10.1016/S0034-4257(02)00078-0

Ganapol, B. D., Johnson, L. F., Hammer, P. D., Hlavka, C. A., \& Peterson, D. L. (1998). LEAFMOD: A new within-leaf radiative transfer model. Remote Sensing of Environment, 63(2), 182-193. http://doi.org/10.1016/S0034-4257(97)00134-X

Gelman, A and Rubin, DB (1992) Inference from iterative simulation using multiple sequences, Statistical Science, 7, 457-511.

Grant, L. (1987). Diffuse and specular characteristics of leaf reflectance, Remote Sensing of Environment 22, 309-322, doi:10.1016/0034-4257(87)90064-2 
Haario, H., Saksman, E., \& Tamminen, J. (2001). An Adaptive Metropolis Algorithm. Bernoulli, 7(2), 223-242. http://doi.org/10.2307/3318737

Haboudane, D., Miller, J. R., Tremblay, N., Zarco-Tejada, P. J., \& Dextraze, L. (2002). Integrated narrow-band vegetation indices for prediction of crop chlorophyll content for application to precision agriculture. Remote Sensing of Environment, 81(2-3), 416-426. http://doi.org/10.1016/S0034-4257(02)00018-4

Hansen, M. C., Stehman, S. V, \& Potapov, P. V. (2010). Quantification of global gross forest cover loss. Proceedings of the National Academy of Sciences of the United States of America, 107(19), 8650-8655. http://doi.org/10.1073/pnas.0912668107

Houborg, R., Fisher, J. B., \& Skidmore, A. K. (2015). Advances in remote sensing of vegetation function and traits. International Journal of Applied Earth Observation and Geoinformation. http://doi.org/10.1016/j.jag.2015.06.001

Huete, A., Didan, K., Miura, T., Rodriguez, E. P., Gao, X., \& Ferreira, L. G. (2002). Overview of the radiometric and biophysical performance of the MODIS vegetation indices. Remote Sensing of Environment, 83(1-2), 195-213. http://doi.org/10.1016/S0034-4257(02)00096-2

Hunt, E. R. J., Wang, L., Qu, J. J., \& Hao, X. (2012). Remote sensing of fuel moisture content from canopy water indices and normalized dry matter index. Journal of Applied Remote Sensing, 6. http://doi.org/10.1117/1.JRS.6.061705

Jacquemoud, S., \& Baret, F. (1990). PROSPECT: A model of leaf optical properties spectra. Remote Sensing of Environment, 34(2), 75-91. http://doi.org/10.1016/0034-4257(90)90100$\mathrm{Z}$

Jacquemoud, S., Baret, F., Andrieu, B., Danson, F. M., \& Jaggard, K. (1995). Extraction of vegetation biophysical parameters by inversion of the PROSPECT+SAIL models on sugar beet canopy reflectance data. Application to TM and AVIRIS sensors. Remote Sensing of Environment, 52(3), 163-172. http://doi.org/10.1016/0034-4257(95)00018-V

Jacquemoud, S., Verhoef, W., Baret, F., Bacour, C., Zarco-Tejada, P. J., Asner, G. P., François, C., \& Ustin, S. L. (2009). PROSPECT + SAIL models: A review of use for vegetation characterization. Remote Sensing of Environment, 113(SUPPL. 1), S56-S66. http://doi.org/10.1016/j.rse.2008.01.026

Knyazikhin, Y., Martonchik, J. V., Diner, D. J., Myneni, R. B., Verstraete, M., Pinty, B., \& Gobron, N. (1998). Estimation of vegetation canopy leaf area index and fraction from atmosphere-corrected MISR data. Journal of Geophysical Research, 103, 239-256.

Knyazikhin, Y., Schull, M. A., Stenberg, P., Mõttus, M., Rautiainen, M., Yang, Y., Marshak, A., Carmona, P.L., Kaufmann, R. K., Lewis, P. et al. (2013). Hyperspectral remote sensing of foliar nitrogen content. Proceedings of the National Academy of Sciences of the United States of America, 110(3), E185-92. http://doi.org/10.1073/pnas.1210196109 
Kobayashi H., Baldocchi D.D., Ryu Y., Chen Q., Ma S., Osuna J.L., Ustin S.L. (2012). Modeling energy and carbon fluxes in a heterogeneous oak woodland: A three-dimensional approach. Agricultural and Forest Meteorology 152: 83-100.

Kuusk, A. (2001). A two-layer canopy reflectance model. Journal of Quantitative Spectroscopy and Radiative Transfer, 71(1), 1-9. http://doi.org/10.1016/S0022-4073(01)00007-3

Laurent, V. C. E., Schaepman, M. E., Verhoef, W., Weyermann, J., \& Chávez, R. O. (2014). Bayesian object-based estimation of LAI and chlorophyll from a simulated Sentinel-2 topof-atmosphere radiance image. Remote Sensing of Environment, 140, 318-329. http://doi.org/10.1016/j.rse.2013.09.005

Lauvernet, C., Baret, F., Hascoët, L., Buis, S., \& Le Dimet, F. X. (2008). Multitemporal-patch ensemble inversion of coupled surface-atmosphere radiative transfer models for land surface characterization. Remote Sensing of Environment, 112(3), 851-861. http://doi.org/10.1016/j.rse.2007.06.027

Le Maire, G., François, C., \& Dufrêne, E. (2004). Towards universal broad leaf chlorophyll indices using PROSPECT simulated database and hyperspectral reflectance measurements. Remote Sensing of Environment, 89(1), 1-28. http://doi.org/10.1016/j.rse.2003.09.004

LeBauer, D. S., Wang, D., Richter, K. T., Davidson, C. S., \& Dietze, M. C. (2013). Facilitating feedbacks between field measurements and ecosystem models. Ecological Monographs, 83(2), 133-154.

Lepine, L. C., Ollinger, S. V., Ouimette, A. P., \& Martin, M. E. (2016). Examining spectral reflectance features related to foliar nitrogen in forests: Implications for broad-scale nitrogen mapping. Remote Sensing of Environment, 173, 174-186. http://doi.org/10.1016/j.rse.2015.11.028

Leprieur, C., Verstraete, M. M., \& Pinty, B. (1994). Evaluation of the performance of various vegetation indices to retrieve vegetation cover from AVHRR data. Remote Sensing Reviews, 10(4), 265-284. http://doi.org/10.1080/02757259409532250

Lewis, P., \& Disney, M. (2007). Spectral invariants and scattering across multiple scales from within-leaf to canopy. Remote Sensing of Environment, 109(2), 196-206. http://doi.org/10.1016/j.rse.2006.12.015

Li, P. H., \& Wang, Q. (2013). Retrieval of chlorophyll for assimilating branches of a typical desert plant through inversed radiative transfer models. International Journal of Remote Sensing, 34(7), 2402-2416. http://doi.org/10.1080/01431161.2012.744859

Li, P., \& Wang, Q. (2011). Retrieval of leaf biochemical parameters using PROSPECT inversion: A new approach for alleviating ill-posed problems. IEEE Transactions on Geoscience and Remote Sensing, 49(7), 2499-2506. http://doi.org/10.1109/TGRS.2011.2109390 
Liu, C., Chen, M., Shi, R., \& Gao, W. (2014). Retrievals of aerosol optical depth and total column ozone from Ultraviolet Multifilter Rotating Shadowband Radiometer measurements based on an optimal estimation technique. Frontiers of Earth Science, 8(4), 610-624. http://doi.org/10.1007/s11707-014-0455-6

Liu, J., Pattey, E., \& Jégo, G. (2012). Assessment of vegetation indices for regional crop green LAI estimation from Landsat images over multiple growing seasons. Remote Sensing of Environment, 123, 347-358. http://doi.org/10.1016/j.rse.2012.04.002

Loveland, T. R., Reed, B. C., Brown, J. F., Ohlen, D. O., Zhu, Z., Yang, L., \& Merchant, J. W. (2000). Development of a global land cover characteristics database and IGBP DISCover from $1 \mathrm{~km}$ AVHRR data. International Journal of Remote Sensing, 21(6-7), 1303-1330. http://doi.org/10.1080/014311600210191

Malenovský, Z., Albrechtová, J., Lhotáková, Z., Zurita-Milla, R., Clevers, J. G. P. W., Schaepman, M. E., \& Cudlín, P. (2006). Applicability of the PROSPECT model for Norway spruce needles. International Journal of Remote Sensing, 27(24), 5315-5340. http://doi.org/10.1080/01431160600762990

Medvigy, D., Wofsy, S. C., Munger, J. W., Hollinger, D. Y., \& Moorcroft, P. R. (2009). Mechanistic scaling of ecosystem function and dynamics in space and time: Ecosystem Demography model version 2. Journal of Geophysical Research: Biogeosciences, 114(1), 1-21. http://doi.org/10.1029/2008JG000812

Moorthy, I., Miller, J. R., \& Noland, T. L. (2008). Estimating chlorophyll concentration in conifer needles with hyperspectral data: An assessment at the needle and canopy level. Remote Sensing of Environment, 112(6), 2824-2838. http://doi.org/10.1016/j.rse.2008.01.013

Mousivand, A., Menenti, M., Gorte, B., \& Verhoef, W. (2015). Multi-temporal, multi-sensor retrieval of terrestrial vegetation properties from spectral-directional radiometric data. Remote Sensing of Environment, 158, 311-330. http://doi.org/10.1016/j.rse.2014.10.030

Myneni, R. B., Hoffman, S., Knyazikhin, Y., Privette, J. L., Glassy, J., Tian, Y., Wang, Y., Song, X., Zhang, Y., Smith, G. R. et al. (2002). Global products of vegetation leaf area and fraction absorbed PAR from year one of MODIS data. Remote Sensing of Environment, 83(1-2), 214-231. http://doi.org/10.1016/S0034-4257(02)00074-3

Ni-Meister, W., Yang, W., \& Kiang, N. Y. (2010). A clumped-foliage canopy radiative transfer model for a global dynamic terrestrial ecosystem model. I: Theory. Agricultural and Forest Meteorology, 150(7-8), 881-894. http://doi.org/10.1016/j.agrformet.2010.02.009

Pinty, B., Andredakis, I., Clerici, M., Kaminski, T., Taberner, M., Verstraete, M. M., Gobron, N., Plummer, S., \& Widlowski, J.-L. (2011). Exploiting the MODIS albedos with the TwoStream Inversion Package (JRC-TIP): 1. Effective leaf area index, vegetation, and soil 
properties. Journal of Geophysical Research: Atmospheres, 116, 1-20. http://doi.org/10.1029/2010JD015372

Plummer, M., Best, N., Cowles, K., Vines, K., Sarkar, D., \& Almond, R. coda: Output analysis and diagnostics for MCMC. https://cran.r-project.org/web/packages/coda/.

Poorter, H., Niinemets, U., Poorter, L., Wright, I. J., \& Villar, R. (2009). Causes and consequences of variation in leaf mass per area (LMA): a meta-analysis. New Phytologist, $182,565-588$.

Quaife, T., Lewis, P., De Kauwe, M., Williams, M., Law, B. E., Disney, M., \& Bowyer, P. (2008). Assimilating canopy reflectance data into an ecosystem model with an Ensemble Kalman Filter. Remote Sensing of Environment, 112(4), 1347-1364. http://doi.org/10.1016/j.rse.2007.05.020

R Development Core Team. (2008). R: A Language and Environment for Statistical Computing. Vienna, Austria.

Serbin SP (2012) Spectroscopic determination of leaf nutritional, morphological, and metabolic traits. PhD dissertation. UW- Madison, Madison, WI, USA

Serbin, S. P., Dillaway, D. N., Kruger, E. L., \& Townsend, P. A. (2012). Leaf optical properties reflect variation in photosynthetic metabolism and its sensitivity to temperature. Journal of Experimental Botany, 63(1), 489-502. http://doi.org/10.1093/jxb/err294

Serbin, S. P., Singh, A., McNeil, B. E., Kingdon, C. C., \& Townsend, P. A. (2014). Spectroscopic determination of leaf morphological and biochemical traits for northern temperate and boreal tree species. Ecological Applications, 24(September), 140401105029006. http://doi.org/10.1890/13-2110.1

Singh, A., Serbin, S. P., McNeil, B. E., Kingdon, C. C., \& Townsend, P. A. (2015). Imaging spectroscopy algorithms for mapping canopy foliar chemical and morphological traits and their uncertainties. Ecological Applications.

Sliwa, K., Wilson, C. D., Iono, D., Peck, A., \& Matsushita, S. (2014). Around the ring we go: the cold, dense ring of molecular gas in NGC 1614. The Astrophysical Journal, 796(1), L15. http://doi.org/10.1088/2041-8205/796/1/L15

Sullivan, F. B., Ollinger, S. V, Martin, M. E., Ducey, M. J., Lepine, L. C., \& Wicklein, H. F. (2013). Foliar nitrogen in relation to plant traits and reflectance properties of New Hampshire forests. Canadian Journal of Forest Research, 43(1), 18-27. http://doi.org/10.1139/cjfr-2012-0324

Verhoef, W. (1984). Light scattering by leaf layers with application to canopy reflectance modeling: The SAIL model. Remote Sensing of Environment, 16(2), 125-141. http://doi.org/10.1016/0034-4257(84)90057-9 
882

883

884

885

886

887

888

889

890

891

892

893

894

895

896

897

898

899

900

901

902

903

904

905

906

907

908

909

910

911

912

913

914

915

916

917

Wang, Q., \& Li, P. (2013). Canopy vertical heterogeneity plays a critical role in reflectance simulation. Agricultural and Forest Meteorology, 169, 111-121. http://doi.org/10.1016/j.agrformet.2012.10.004

Wang, Z., Skidmore, A. K., Wang, T., Darvishzadeh, R., \& Hearne, J. (2015). Applicability of the PROSPECT model for estimating protein and cellulose+lignin in fresh leaves. Remote Sensing of Environment, 168, 205-218. http://doi.org/10.1016/j.rse.2015.07.007

Wessels, K. J., van den Bergh, F., \& Scholes, R. J. (2012). Limits to detectability of land degradation by trend analysis of vegetation index data. Remote Sensing of Environment, 125, 10-22. http://doi.org/10.1016/j.rse.2012.06.022

Wilkman, O., Muinonen, K., Videen, G., Josset, J.-L., \& Souchon, A. (2014). Lunar photometric modelling with SMART-1/AMIE imaging data. Journal of Quantitative Spectroscopy and Radiative Transfer, 146, 529-539. http://doi.org/10.1016/j.jqsrt.2014.01.015

Wright, I. J., Reich, P. B., Westoby, M., Ackerly, D. D., Baruch, Z., Bongers, F., CavenderBares, J., Chapin, T., Cornelissen, J. H. C., Diemer, M. et al. (2004). The worldwide leaf economics spectrum. Nature, 428(6985), 821-827. http://doi.org/10.1038/nature02403

Yao, Y., Liu, Q., Liu, Q., \& Li, X. (2008). LAI retrieval and uncertainty evaluations for typical row-planted crops at different growth stages. Remote Sensing of Environment, 112(1), 94106. http://doi.org/10.1016/j.rse.2006.09.037

Zarco-Tejada, P. J., Guillén-Climent, M. L., Hernández-Clemente, R., Catalina, A., González, M. R., \& Martín, P. (2013). Estimating leaf carotenoid content in vineyards using high resolution hyperspectral imagery acquired from an unmanned aerial vehicle (UAV). Agricultural and Forest Meteorology, 171-172, 281-294. http://doi.org/10.1016/j.agrformet.2012.12.013

Zarco-Tejada, P. J., Miller, J. R., Harron, J., Hu, B., Noland, T. L., Goel, N., Mohammed, G. H., \& Sampson, P. (2004). Needle chlorophyll content estimation through model inversion using hyperspectral data from boreal conifer forest canopies. Remote Sensing of Environment, 89(2), 189-199. http://doi.org/10.1016/j.rse.2002.06.002

Zhang, Q., Xiao, X., Braswell, B., Linder, E., Baret, F., \& Moore, B. (2005). Estimating light absorption by chlorophyll, leaf and canopy in a deciduous broadleaf forest using MODIS data and a radiative transfer model. Remote Sensing of Environment, 99(3), 357-371. http://doi.org/10.1016/j.rse.2005.09.009

Zhang, Q., Xiao, X., Braswell, B., Linder, E., Ollinger, S., Smith, M.-L., Jenkins, J.P., Baret, F., Richardson, A.D., Moore, B. III, \& Minocha, R. (2006). Characterization of seasonal variation of forest canopy in a temperate deciduous broadleaf forest, using daily MODIS data. Remote Sensing of Environment, 105(3), 189-203. http://doi.org/10.1016/j.rse.2006.06.013 
Zhang, Q., Middleton, E. M., Margolis, H. A., Drolet, G. G., Barr, A. A., \& Black, T. A. (2009). Can a satellite-derived estimate of the fraction of PAR absorbed by chlorophyll (FAPARchl) improve predictions of light-use efficiency and ecosystem photosynthesis for a boreal aspen forest? Remote Sensing of Environment, 113(4), 880-888. http://doi.org/10.1016/j.rse.2009.01.002

Zhang, Q., Middleton, E. M., Gao, B. C., \& Cheng, Y. Ben. (2012). Using EO-1 Hyperion to simulate HyspIRI products for a coniferous forest: The fraction of par absorbed by chlorophyll (fAPAR chl) and leaf water content (LWC). IEEE Transactions on Geoscience and Remote Sensing, 50(5 PART 2), 1844-1852. http://doi.org/10.1109/TGRS.2011.2169267

Zhang, Y., Chen, J. M., Miller, J. R., \& Noland, T. L. (2008). Retrieving chlorophyll content in conifer needles from hyperspectral measurements. Canadian Journal of Remote Sensing, 34(3), 296-310.

Zhang, Y., Qu, Y., Wang, J., Liang, S., \& Liu, Y. (2012). Estimating leaf area index from MODIS and surface meteorological data using a dynamic Bayesian network. Remote Sensing of Environment, 127, 30-43. http://doi.org/10.1016/j.rse.2012.08.015

Zhao, F., Guo, Y., Huang, Y., Reddy, K. N., Lee, M. A., Fletcher, R. S., \& Thomson, S. J. (2014). Early detection of crop injury from herbicide glyphosate by leaf biochemical parameter inversion. International Journal of Applied Earth Observation and Geoinformation, 31(1), 78-85. http://doi.org/10.1016/j.jag.2014.03.010 